\title{
Operando Infrared Spectroscopy for the Analysis of Gas-processing Metalloenzymes
}

Sven T. Stripp

Bioinorganic Spectroscopy, Department of Physics, Freie Universität Berlin, Arnimallee 14, 14195 Berlin

sven.stripp@fu-berlin.de

\begin{abstract}
Earth-abundant transition metals like iron, nickel, copper, molybdenum, and vanadium have been identified as essential constituents of the cellular gas metabolism in all kingdoms of life. Associated with biological macromolecules, gas-processing metalloenzymes (GPMs) are formed that catalyse a variety of redox reactions. This includes the reduction of $\mathrm{O}_{2}$ to water by cytochrome $\mathrm{c}$ oxidase ('complex IV'), the reduction of $\mathrm{N}_{2}$ to $\mathrm{NH}_{4}$ by nitrogenase, as well as the reduction of protons to $\mathrm{H}_{2}$ (and oxidation of the later) by hydrogenase. GPMs perform at ambient temperature and pressure, in the presence of water, and often extremely low educt concentrations, thus serving as natural examples for efficient catalysis. Facilitating the design of biomimetic catalysts, biophysicist thrive to understand the reaction principles of GPMs making use of various techniques. In this perspective, I will introduce Fourier-transform infrared spectroscopy in attenuated total reflection configuration (ATR FTIR) for the analysis of GPMs like cytochrome c oxidase, nitrogenase, and hydrogenase. Infrared spectroscopy provides information about the geometry and redox state of the catalytic cofactors, the protonation state of amino acid residues, the hydrogen-bonding network, and protein structural changes. I developed an approach to probe and trigger the reaction of GPMs by gas exchange experiments, exploring the reactivity of these enzymes with their natural reactants. This allows recording sensitive ATR FTIR difference spectra with seconds time resolution. Finally yet importantly, infrared spectroscopy is an electronically non-invasive technique that allows investigating protein samples under biologically relevant conditions, i.e., at ambient temperature and pressure, and in the presence of water.
\end{abstract}

Keywords: Biophysics; Spectroscopy; Physical Chemistry; Enzymes; Bioinorganic Chemistry

\section{Metalloenzymes}

Metalloenzymes are metal-containing proteins that catalyse a variety of fundamental biochemical reactions. Gas-processing metalloenzymes (GPMs), in particular, are key in photosynthesis, respiration, and $\mathrm{N}_{2}$ fixation. ${ }^{1-3}$ While main group metalloenzymes bind individual metal ions that are not directly involved in redox chemistry ${ }^{4-6}$, GPMs utilize redox-active organometallic cofactors based on transitions metals like $\mathrm{Fe}, \mathrm{Ni}, \mathrm{Cu}, \mathrm{Mo}$, and $\mathrm{V}$. The reactivity and structure of these cofactors continues to inspire noble metal-free complexes that mimic biocatalytic reactions of industrial interest. ${ }^{7}$ On the physiological level, GPMs are involved in maintaining proton gradients and the cellular redox balance as well as sensing of toxic and/or messenger-type gases like $\mathrm{CO}$ or NO. ${ }^{8-11}$

Understanding small molecule activation with GPMs is a truly interdisciplinary effort with input from molecular biology, inorganic chemistry, and the physical sciences. In this perspective, I will discuss GPMs 
catalysing $\mathrm{H}_{2}$ oxidation and $\mathrm{H}^{+}$reduction (hydrogenase), $\mathrm{N}_{2}$ and $\mathrm{CO}$ reduction (nitrogenase) as well as $\mathrm{O}_{2}$ reduction by complex IV of the respiratory chain (cytochrome c oxidase). I will focus on operando infrared spectroscopy with reaction control via the gas phase, addressing catalysis under biologically relevant conditions and in the presence of natural reactants like $\mathrm{H}_{2}, \mathrm{CO}$, or $\mathrm{O}_{2}$. Moreover, I will discuss visible light excitation and potential jump experiments to trigger infrared difference spectra.

\section{Hydrogenases}

Hydrogenases are redox enzymes that catalyse $\mathrm{H}_{2}$ oxidation and $\mathrm{H}^{+}$reduction. ${ }^{12}$ Bimetallic hydrogenases are classified as [NiFe]- and [FeFe]-hydrogenases depending on the composition of the organometallic active site cofactor. ${ }^{12-14}$ They utilize a varying number of iron-sulphur clusters, e.g., in electron transfer or $\mathrm{O}_{2}$ reduction. ${ }^{15}$ The monometallic [Fe]-hydrogenases do not catalyse hydrogen turnover per se but facilitate hydride transfer from a guanylylpridinol-coordinated iron site (Fe-GP) to an tetrahydromethanopterin cofactor $\left(\mathrm{H}_{4} \mathrm{MPT}\right) .{ }^{16}$ Moreover, [Fe]-hydrogenases do not bind iron-sulphur clusters. While the molecular details of proton transfer in [NiFe]- and [FeFe]-hydrogenases are fairly well understood $^{17}$, no such data exist for [Fe]-hydrogenase. Figure 1 depicts the active site cofactors of hydrogenase. The carbon monoxide and cyanide ligands $\left(\mathrm{CO} \mathrm{CN}^{-}\right)$characteristically found in all hydrogenases tune the redox potential of the $\mathrm{H}_{2}$ oxidation/ $\mathrm{H}^{+}$reduction reaction and facilitate hydrogen turnover at low overpotential. ${ }^{18}$ Furthermore, the intense absorbance of Fe- $\mathrm{CO}$ and $\mathrm{Fe}-\mathrm{CN}^{-}$in a frequency regime not obscured by protein or solvent bands renders hydrogenase an excellent target for infrared spectroscopic investigations (Section 2).${ }^{19-21}$ The frequency of the cofactor bands is indicative of the ligation pattern, redox and protonation changes, hydrogen bonding, and vibrational coupling, the later which can be analysed to unravel the cofactor geometry. The posttranslational maturation of [FeFe]hydrogenase 22,23 facilitated the generation of organometallic variants of the ' $\mathrm{H}$-cluster', including substitutions of the aminodithiolate (adt) headgroup, sulphur atoms, and iron ions (Figure 1). ${ }^{24-26}$

(A)

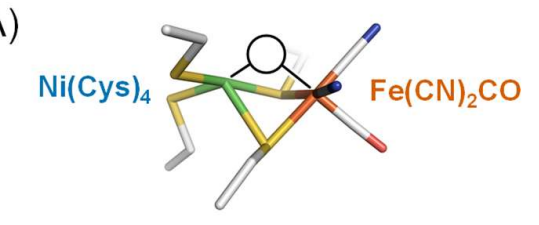

(B)

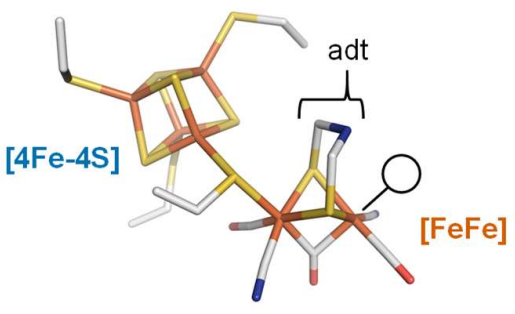

(C)

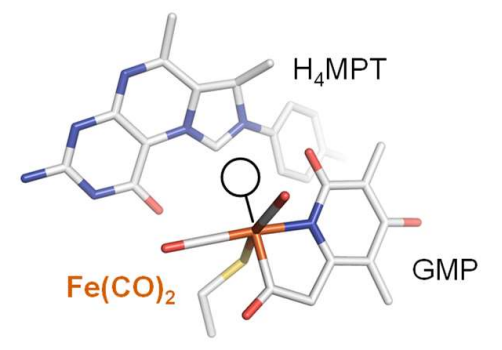

Figure 1 | The active site cofactors of hydrogenase. Circles denotes the open coordination site at each cofactor. (A) Ni-Fe cofactor of [NiFe]-hydrogenase. (B) The H-cluster of [FeFe]-hydrogenase comprises a 
[4Fe-4S] cluster and the catalytic diiron site. (C) The Fe-GMP cofactor of [Fe]-hydrogenase with the $\mathrm{H}_{4} \mathrm{MPT}$ substrate. Drawn after pdb coordinates 3MYR, 4XDC, and 5AWU.

\section{Nitrogenase}

Nitrogenase forms water-soluble, multi-subunit protein complexes that catalyse the reduction of $\mathrm{N}_{2}$ into $\mathrm{NH}_{4}$ and $\mathrm{H}_{2}$ at the expense of $16-40$ equivalents of ATP, depending on the metal composition of the active site cofactor. ${ }^{27}$ The enzyme comprises the so-called 'Fe protein', a homodimer that binds and hydrolyses ATP upon reduction of an all-ferrous [4Fe-4S] cluster. ${ }^{28}$ Electrons are transferred from the Fe protein to an [8Fe-7S] compound, the ' $\mathrm{P}$-cluster', which charges a [X-7Fe-9S-C] cluster, where $\mathrm{X}$ may be $\mathrm{M}, \mathrm{V}$, or Fe (Figure 2). ${ }^{29}$ Both these moieties reside on a heterotetramer that forms the core of nitrogenase. In variance to hydrogenase, none of these cofactors intrinsically carries $\mathrm{CO}$ or $\mathrm{CN}^{-}$ligands. However, both compounds are known as substrates and/or inhibitor of nitrogenase activity ${ }^{30}$ and have been exploited to investigate potential binding site at the $[\mathrm{X}-7 \mathrm{Fe}-9 \mathrm{~S}-\mathrm{C}]$ cluster by $\mathrm{EPR}^{31}$ and $\mathrm{IR}$ spectroscopy. ${ }^{32-34}$ Figures 2 illustrates how CO coordinates in Fe-Fe bridging ( $\mu \mathrm{CO}$ ) and/or terminal position ( $t C O) .{ }^{35}$ Moreover, VFe nitrogenase has been shown to catalyse the conversion of $\mathrm{CO}$ and $\mathrm{H}_{2}$ into various carbohydrates. ${ }^{36}$ Operando IR spectroscopy can be used to distinguish the different reaction pathways. Such side trails may also involve the Fe protein whose [4Fe-4S] cluster was suggested to bind $\mathrm{CO}_{2}$, which would give rise to distinct IR marker bands. ${ }^{37,38}$

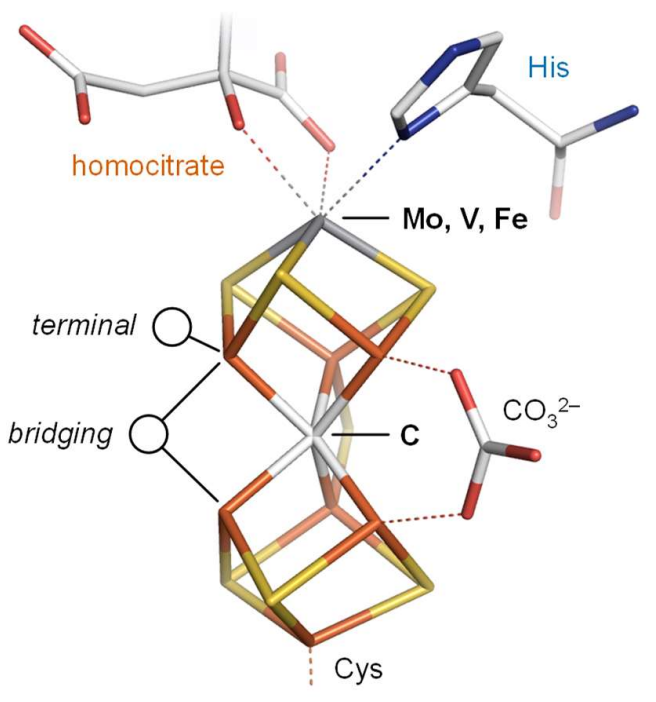

Figure 2 | The active site cofactor of nitrogenase. The heteroatom (dark grey) may be Mo, V, or Fe. The Fe-Fe bridging binding site may be occupied by $\mathrm{S}, \mathrm{N}$, or $\mathrm{CO}$. A terminal $\mathrm{CO}$ ligand has been shown to bind in the indicated position. Note the presence of $\mathrm{CO}_{3}{ }^{2-}$ ligand. Drawn after pdb coordinates 6FEA.

\section{Cytochrome c oxidase}

Cytochrome coxidase $(\mathrm{CcO})$ is the fourth and final transmembrane protein complex in the mitochondrial electron transport chain. They belong to the family of hem-copper oxidases. ${ }^{39}$ The enzyme catalyses the reduction of $\mathrm{O}_{2}$ to water and pumps protons across the mitochondrial membrane. ${ }^{40}$ The core of $\mathrm{CcO}$ is formed by subunits I and II. The later facilitates contact with the natural electron donor, cytochrome $\mathrm{c}$, and binds a di-copper site $\left(\mathrm{Cu}_{A}\right)$ as redox centre. From $\mathrm{Cu}_{A}$, electrons are transferred to heme a and the 'binuclear centre' (BNC) that is formed by heme $\mathrm{a}_{3}$ and a singular copper ion, $\mathrm{Cu}_{\mathrm{B}}$, coordinated by three 
histidine residues. A cross-linked tyrosine may serve as proton donor in the catalytic reaction ${ }^{41}$ whereas arginine and glutamic acid residues are discussed to be involved in proton pumping. ${ }^{42}$ Figure 3 depicts the BNC of $\mathrm{CcO}$ from $B$. taurous. ${ }^{43}$ The high-valent iron ion in heme a is coordinated by two histidines while only one histidine is found at heme $a_{3}$. This leaves one open coordination site at the iron ion of heme $a_{3}$ and $\mathrm{Cu}_{B}$, each. None of the metal centres in $\mathrm{CcO}$ intrinsically carries $\mathrm{CO}$ or $\mathrm{CN}^{-}$ligands, but both heme $\mathrm{a}_{3}$ and $\mathrm{Cu}_{\mathrm{B}}$ can bind a variety of inhibiting ligands ${ }^{44}$ that have been exploited to explore the binuclear centre by IR spectroscopy. For example, the 'fully reduced' (FR or $\mathrm{R}_{4}$ ) enzyme binds a single CO ligand at heme $\mathrm{a}_{3}$ $\left(\mathrm{Fe}^{2+}\right.$, a similarity with heme proteins like myoglobin) that can be photolyzed and transiently transferred to $\mathrm{Cu}_{B}$, which is believed to mimic the reduction of $\mathrm{O}_{2}{ }^{45}$ In the 'mixed valence' state (MV or $\left.\mathrm{R}_{2}\right) \mathrm{Cu}_{A}$ and heme a are oxidized, which shifts the $\mathrm{CO}$ band at heme $\mathrm{a}_{3}$ to higher energies. Cyanide primarily binds to the oxidized heme $\mathrm{a}_{3}$ site $\left(\mathrm{Fe}^{3+}\right)$ and $\mathrm{Cu}_{\mathrm{B}}$ irrespective of redox state. ${ }^{46}$

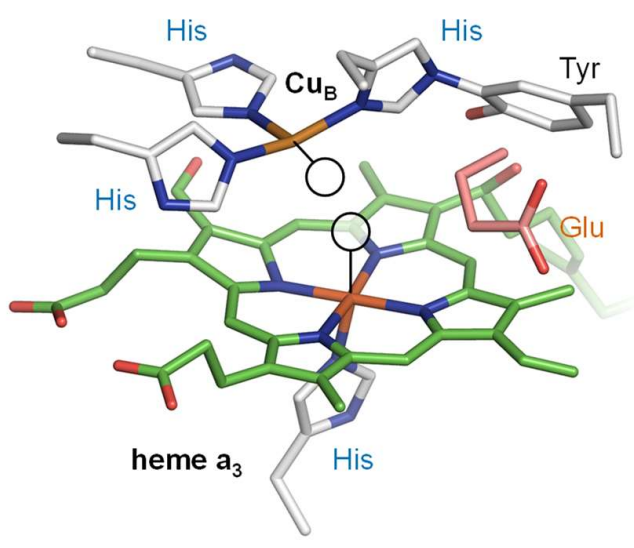

Figure 3 | The active site cofactor of cytochrome c oxidase. The binuclear centre (BNC) comprises of heme $\mathrm{a}_{3}$ and $\mathrm{Cu}_{\mathrm{B}}$ both that display an open binding site. Note the covalent bond between histidine and tyrosin. The glutamic acid residue is important in proton transfer. Drawn after pdb coordinates 5WAU.

\section{Infrared Spectroscopy}

Understanding the catalytic mechanism of GPMs, structural biology and molecular biophysics must go together. This includes UV/visible and EPR spectroscopy as well as XAS and Mössbauer spectroscopy. Vibrational spectroscopy is a valuable tool investigating metal-ligand bonds that often happen to be Raman-active, e.g., in iron-sulphur clusters. ${ }^{47}$ Bonds with a change in dipole moment along the normal coordinate are less likely to exhibit a Raman shift but absorb infrared radiation. While ligands like $\mathrm{CO}, \mathrm{CN}^{-}$ , and $\mathrm{CO}_{2}$ are easily detected by Fourier-transform infrared (FTIR) spectroscopy in the spectral 'window' between $2600-1800 \mathrm{~cm}^{-1}$, many signals are obscured by the vibrations of the protein backbone and liquid water. ${ }^{48}$ Figure 4 depicts the different amide $(\mathrm{N}-\mathrm{H}$ and $\mathrm{C}=\mathrm{O})$, carbohydrate $(\mathrm{CH})$, and water modes $(\mathrm{OH}$ and $\mathrm{HOH}$ ). 


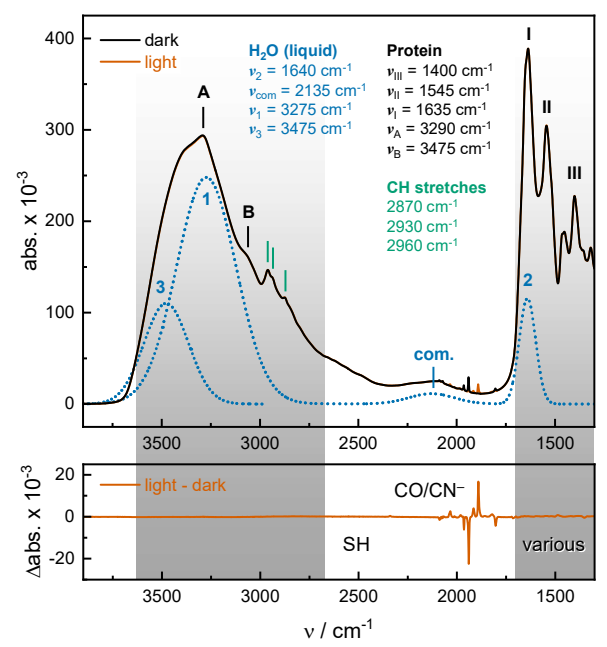

Figure 4 | Absorbance and difference spectra. The absorbance spectra in the upper panel highlight the vibrational contributions from liquid water (dotted blue lines) and protein. Bands around $2900 \mathrm{~cm}^{-1}$ (green) are assigned to $\mathrm{CH}$ stretches. A film of [FeFe]-hydrogenase $\mathrm{CrHydA1}$ and redox dye was recorded in the dark (black) and upon irradiation with LED light (brown). Changes are seemingly restricted to the $\mathrm{CO} / \mathrm{CN}^{-}$'spectral window' between $2150-1750 \mathrm{~cm}^{-1}$. Only upon calculating the 'light - dark' difference spectrum (lower panel) subtle changes become visible in the frequency regimes obscured by the protein and water absorbance bands. In the shaded area, 'various' maybe $\mathrm{COOH}$ and $\mathrm{COO}^{-}$, amide I and II, or specific cofactor/coenzyme bands. Due to low absorbance, $\mathrm{SH}$ bands are only visible in difference spectra.

FTIR difference spectroscopy allows extracting cofactor signals across a wide energy regime when changes are triggered by visible light, e.g., for the analysis of chromoproteins. ${ }^{49}$ Despite singular exceptions ${ }^{50}$, GPMs do not show catalytic photochemistry. Irradiation experiments are important nevertheless: photochemical 'side reactions' and redox dyes allow addressing well-defined state transitions of GPMs. As an example, Figure 4 shows the light-induced reduction of [FeFe]-hydrogenase $\mathrm{CrHydA} 1$ in the presence of redox dye eosin $Y$ and the resulting 'light - dark' difference spectrum. Another popular operando approach is FTIR spectro-electrochemistry (SEC), where redox chemistry is induced or the reaction of the enzyme to electrical fields is studied. ${ }^{51,52}$ But while photochemistry often demands cryogenic temperatures to 'freeze-trap' defined intermediates and SEC puts the enzymes in contact with artificial redox partners, stirring the reactivity of GPMs via the gas phase represents a natural triggering approach. For this, the enzyme must be available to gas exchanges.

\section{Attenuated Total Reflection}

Commonly, FTIR spectroscopy is performed in transmission configuration. Concentrated sample solution is pipetted on an IR-transparent window (e.g. $\mathrm{CaF}_{2}$ or $\mathrm{BaF}_{2}$ ), carefully dried, occasionally rehydrated or deuterated, and sealed with a second window. ${ }^{53}$ The setup comprises a spacer of $\sim 50 \mu \mathrm{m}$ between the windows that guarantees maximal absorbance. Such 'sandwich samples' are exceptionally durable and used to trigger photo- and electrochemical reactions while recording IR absorbance spectra. ${ }^{51-53}$ However, they do not allow for a controlled exchange of the gas phase and the sample state has to be adjusted ahead of the actual measurement. In attenuated total reflection (ATR) configuration, the IR beam forms an evanescent wave at the surface of an IR-transparent, high-refractive index crystal (Figure 5). The penetration depth of the evanescent wave critically depends on the difference in refractive index between 
crystal and sample, the angle of incidence, and the IR frequency. ${ }^{54}$ For $45^{\circ}$ and at $2000 \mathrm{~cm}^{-1}$, typical values range from $\sim 2 \mu \mathrm{m}(\mathrm{ZnS})$ to $\sim 1 \mu \mathrm{m}$ (diamond) and $\sim 0.5 \mu \mathrm{m}$ (Si). ${ }^{55}$ The penetration depth further decreases towards higher frequencies. In transmission configuration, the effective pathlength is independent of frequency and usually one order of magnitude higher. Near-field ATR FTIR spectroscopy is achieved exploiting signal enhancement at plasmonic media, i.e., in surface-enhanced infrared absorbance spectroscopy (SEIRAS), as discussed elsewhere. ${ }^{56}$

(A)

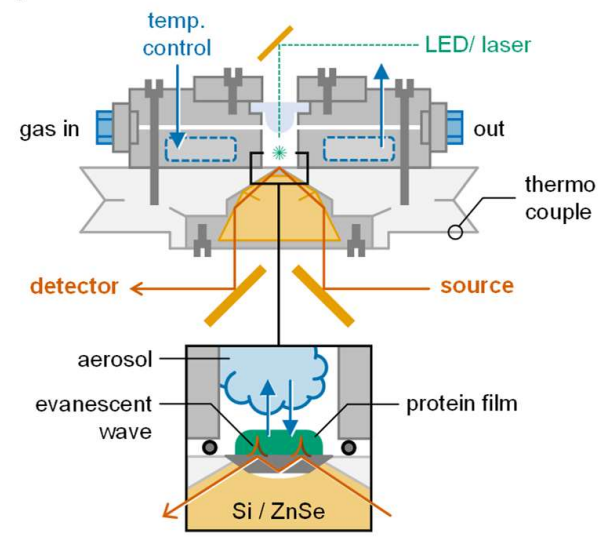

(B)

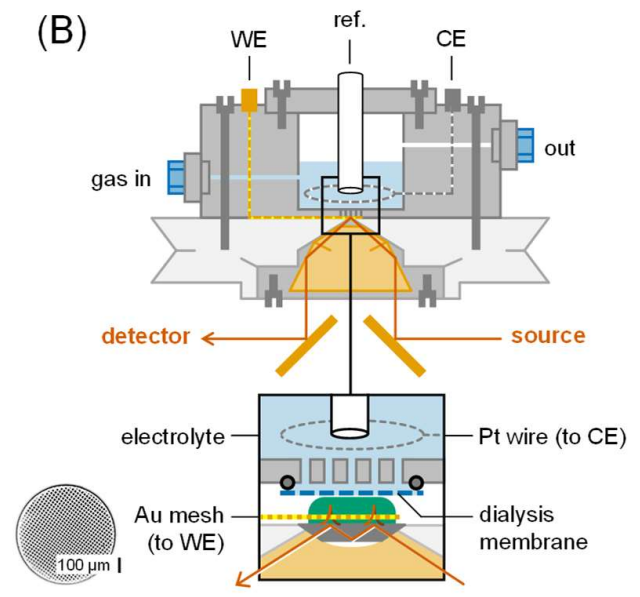

Figure 5 | Experimental set-up for operando ATR FTIR spectroscopy. (A) ATR crystal plate including a ZnSe focus element and the Si crystal. A custom-made titration cell with various in- and outlets for gases as well as temperature and pressure control is screwed to the crystal plate. Additionally, a transparent window or lens allows for visible light irradiation with a LED or laser source. The inset depicts the hydrated protein film as probed by the evanescent field. (B) Spectro-electrochemical titration cell. The sample is in contact with a gold mesh (WE) and a platinum wire (CE) via the electrolyte buffer (purged by inert or reactive gas). Dilution is precluded by a $10 \mathrm{kDa}$ dialysis membrane (inset). A microscopic image of the gold mesh is shown.

The insets in Figure 5 illustrate how the IR beam is fed to the crystal from below while the sample is deposited on top of the crystal, where the actual absorption occurs. ATR FTIR spectroscopy is wellestablished for the analysis for transmembrane or membrane-associated proteins ${ }^{57-61}$ including $\mathrm{CcO}^{62}$ Prepared in detergent, nano discs, or lipid-reconstituted form membrane proteins constitute hydrophobic films that can be overlaid with aqueous buffer for functional analyses. However, GPMs like hydrogenase and nitrogenase are water-soluble and do not form stable films in an aqueous environment. To this end, we pioneered a technique that provides solvent via the gas phase, i.e., in form of an aerosol. ${ }^{63}$ Figure 6 shows how dry gas is send through a wash bottle of buffer or reactant solution taking up water gas and microscopic droplets of liquid water. Fed to the protein film on top of the ATR crystal, the hydroscopic sample absorbs 'humidity' and forms stable, hydrated protein films. This approach facilitates gas titrations and functional analyses of GPMs by ATR FTIR spectroscopy, e.g., when the inert 'carrier gas' is mixed with reactive gases (Section 4) or the film is subjected to visible light or changes in electrical potential (Section 5). But first, the preparation of stable protein films must be established. 


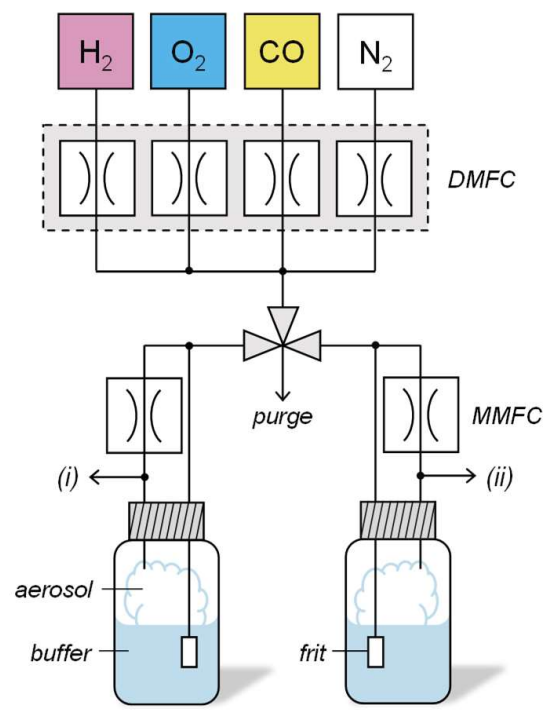

Figure 6 | Preparation of aerosol. Reactive gases like $\mathrm{H}_{2}, \mathrm{O}_{2}$, or $\mathrm{CO}$ are injected into a constant stream of inert carrier gas (e.g., $\mathrm{N}_{2}$ ). The gas flow is controlled by digital mass flow controllers (DMFC). The gas mixture is passed through wash bottle (i) or (ii) comprising $\mathrm{H}_{2} \mathrm{O}$ or $\mathrm{D}_{2} \mathrm{O}$, different buffer compositions, or reactant solution. Thereby, an aerosol is formed. Different levels of 'humidity' are adjusted via manual mass flow controllers (MMFC). The aerosol is sent to the gas titration cell (Figure 5).

\section{Preparation of Protein Films}

The nature of sample preparation in ATR configuration allows using protein solution of relatively low concentration (i.e., between $50-500 \mu \mathrm{M}$, see below). Throughout sample preparation, protein concentration and hydration level are followed in real time. First, the ATR crystal is recorded as background before a small volume of protein solution (e.g., $1 \mu \mathrm{L}$ ) is pipetted onto the surface. The diluted protein solution resembles the IR absorbance spectrum of liquid water but subjected to a constant stream of dry carrier gas characteristic protein bands appear over time (Figure 7A). The concentration of the protein solution increases until a relatively dry 'protein cake' is formed. Note that the formation of (salt) crystals often diminishes the absorbance of protein cake. The relative water content differs between protein samples and depending on additives like salt, detergent, or glycerol; however, a protein sample with less than $20 \%$ water is achieved only upon lyophilization. ${ }^{64}$ 
(A)

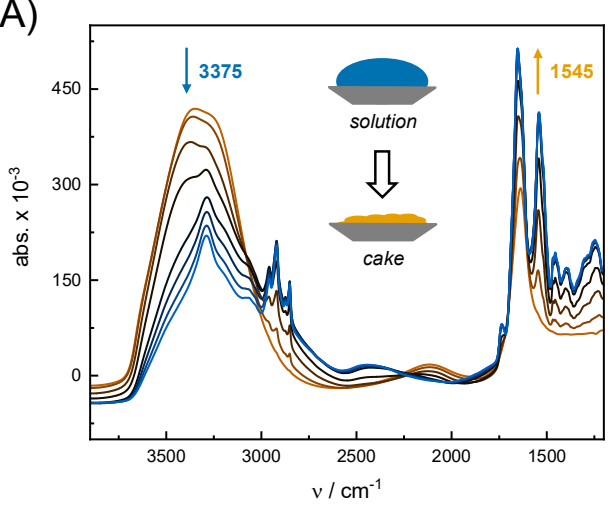

(C)

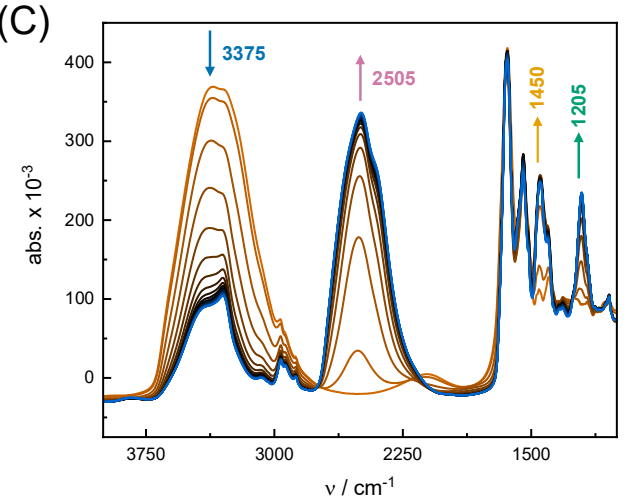

(B)

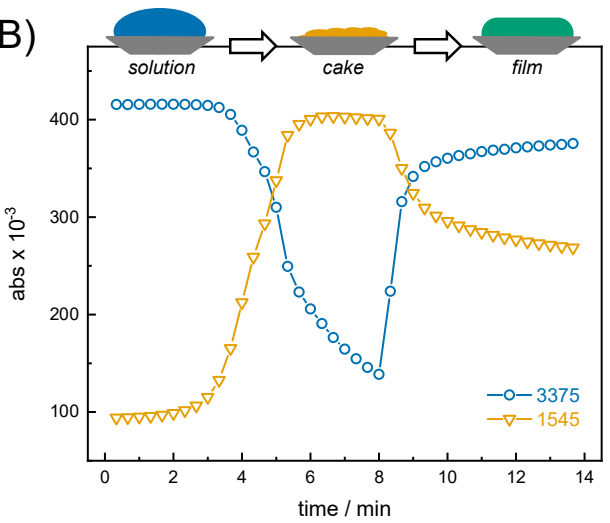

(D)
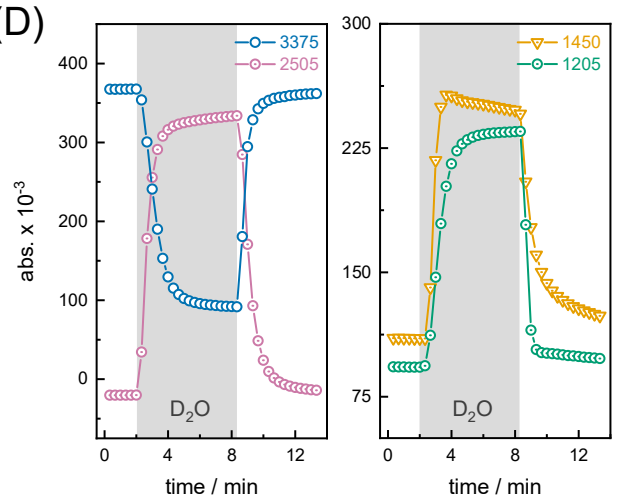

Figure 7 | From protein solution to protein film. (A) Formation of a dry 'protein cake' from protein solution. Example: $\mathrm{CcO}$ from $R$. sphaeroides reconstituted in $E$. coli polar lipids. (B) Plotting the intensity at $3375 \mathrm{~cm}^{-1}\left(\mathrm{~V}_{\mathrm{OH}}\right)$ and $1545 \mathrm{~cm}^{-1}$ (amide II), the formation of the protein film can be followed over time. (C) $\mathrm{H} / \mathrm{D}$ exchange in the presence of $\mathrm{D}_{2} \mathrm{O}$. Prominent bands are highlighted. (D) The process is completely reversible. The marker bands from panel $\mathrm{C}$ are assigned to $\mathrm{OH}$ and $\mathrm{OD}$ stretching ( 3375 and $2505 \mathrm{~cm}^{-1}$ ), $\mathrm{D}_{2} \mathrm{O}$ bending $\left(1205 \mathrm{~cm}^{-1}\right)$, and amide $\mathrm{II}^{\prime}\left(1450 \mathrm{~cm}^{-1}\right)$. Example: VFe nitrogenase from $A$. vinelandii.

In the next step, carrier gas aerosol is used to re-hydrate the protein cake and form a concentrated, reactive protein film. This is facilitated by the natural affinity of soluble proteins to water but also works for membrane-bound proteins. Note the difference in amide II intensity between protein solution, protein cake, and the hydrated protein film: although the water level is nearly similar in the hydrated film ( $10 \%$ difference), more than $50 \%$ of the amide II band intensity is preserved (Figure 7B).

The hydration protocol can be used to exchange the solvent, perform $\mathrm{pH}$ titrations, or enrich the protein film with soluble reactants via the aerosol. ${ }^{63}$ Moreover, it facilitates deuteration when the aqueous buffer is exchanged against deuterium oxide ('heavy water', ${ }^{2} \mathrm{H}_{2} \mathrm{O}$, or $\mathrm{D}_{2} \mathrm{O}$ ) where the mass difference between $\mathrm{H}$ and $\mathrm{D}$ causes a significant shift to lower energies. Figure $7 \mathrm{C}$ demonstrates the reversible exchange of $\mathrm{H}_{2} \mathrm{O}$ and $\mathrm{D}_{2} \mathrm{O}$ bands over time. Protein backbone vibrations that are involved in the H/D exchange shift accordingly (e.g., amide II at $1545 \mathrm{~cm}^{-1}$ and amide II' at $1450 \mathrm{~cm}^{-1}$ ). Deuteration and hydration are mutually reversible, as demonstrated in Figure 7D. Understanding H/D isotope effects is key to understanding hydrogen bonding interations ${ }^{49}$ and hydride chemistry. ${ }^{65}$

The relation between sample concentration and sample film quality is not straight-forward and should be evaluated for each sample individually. ${ }^{63}$ In principal, very low concentrations should be avoided but high 
concentrations do not guarantee for optimal films, either. Moreover, due to the low penetration depth of the evanescent wave stacking sample does not result in better absorbing protein films. Figure $\mathbf{8 A}$ compares the IR spectra of hydrated protein films between $50 \mu \mathrm{M}$ and $400 \mu \mathrm{M}$ starting concentration. Surprisingly, less protein in solution gives protein films of higher density. Detergents and cryoprotectants like glycerol or sucrose delay the formation of protein films or can impede the de-hydration process at all. While the perfect ATR FTIR sample is diluted in pure water often a compromise between sample integrity and applicability must be found. Complex samples behave even less predictable than pure protein samples. Figure 8B shows IR spectra of $E$. coli cell suspension diluted in four steps over eight orders of magnitude. Maximal amide II intensity was achieved upon diluting the suspension $\times 100$, afterwards the protein density in the film continuously declined. Such data is relevant as enzymes can be analysed by IR spectroscopy within the context of living cells. ${ }^{66,67}$
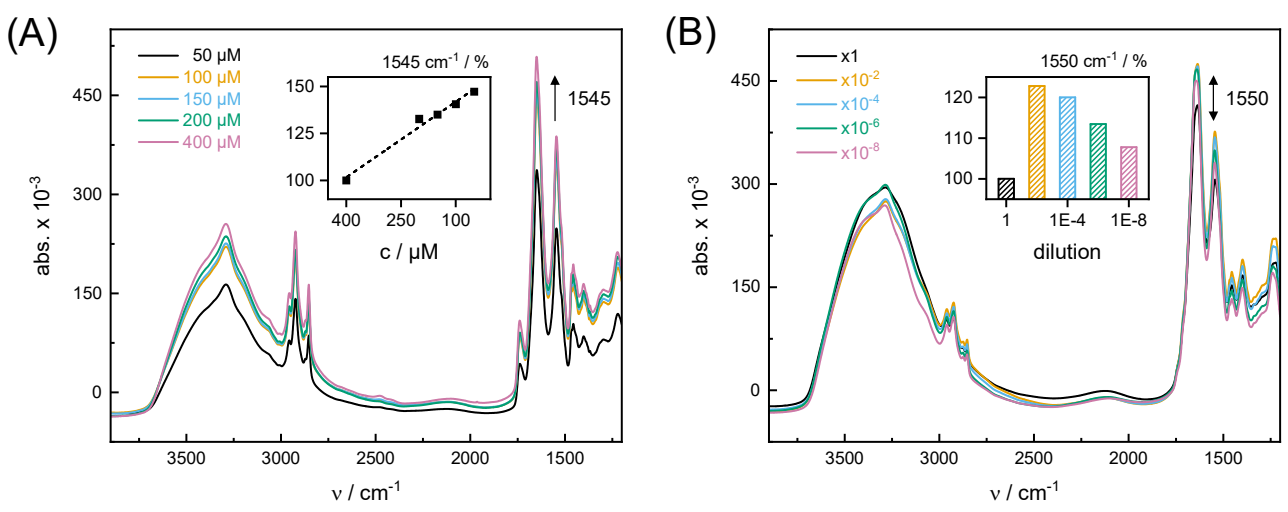

Figure 8 | Influence of sample concentration. (A) Protein solution between $50 \mu \mathrm{M}$ and $400 \mu \mathrm{M}$ was used to prepare protein films. Plotting the amide II band intensity at $1545 \mathrm{~cm}^{-1}$ against concentration illustrate how less protein gives films of higher density (inset). Example: $\mathrm{CcO}$ from $R$. sphaeroides reconstituted in E. coli polar lipids. (B) A suspension of viable $E$. coli cells was diluted up to $10^{8}$ times and used to prepare a hydrated sample film $\left(x 1 \sim O D_{600}=1.5\right)$. The amide II band intensity shows that diluting the suspension by a factor of 100 gave a significantly higher sample concentration in the film (1550 $\mathrm{cm}^{-1}$, see inset). Further dilution decreased the film concentration gradually.

Our setup for ATR FTIR spectroscopy facilitates control over several parameters. For example, Figure 9A depicts the influence of temperature on hydration level and protein concentration of the sample film (constant pressure). The temperature is adjusted via an external circulation pump and measured by a digital thermocouple attached between spectrometer and crystal plate (Figure 4). ${ }^{68}$ Technically, temperatures down to $-30^{\circ} \mathrm{C}$ can be achieved but condensation and/or deposition of the aerosol practically impede long-running measurements below $5^{\circ} \mathrm{C}$. Within several tens of minutes, however, the setup allows investigating the global influence of temperature on the protein film. Figure $9 \mathrm{~A}$ shows how the sample takes up increasingly less humidity from the aerosol between $-5^{\circ} \mathrm{C}$ and $35^{\circ} \mathrm{C}$. This results from the temperature-dependent phase equilibrium of liquid and gaseous water and reflects in a nearly linear correlation between hydration level and temperature (inset). 

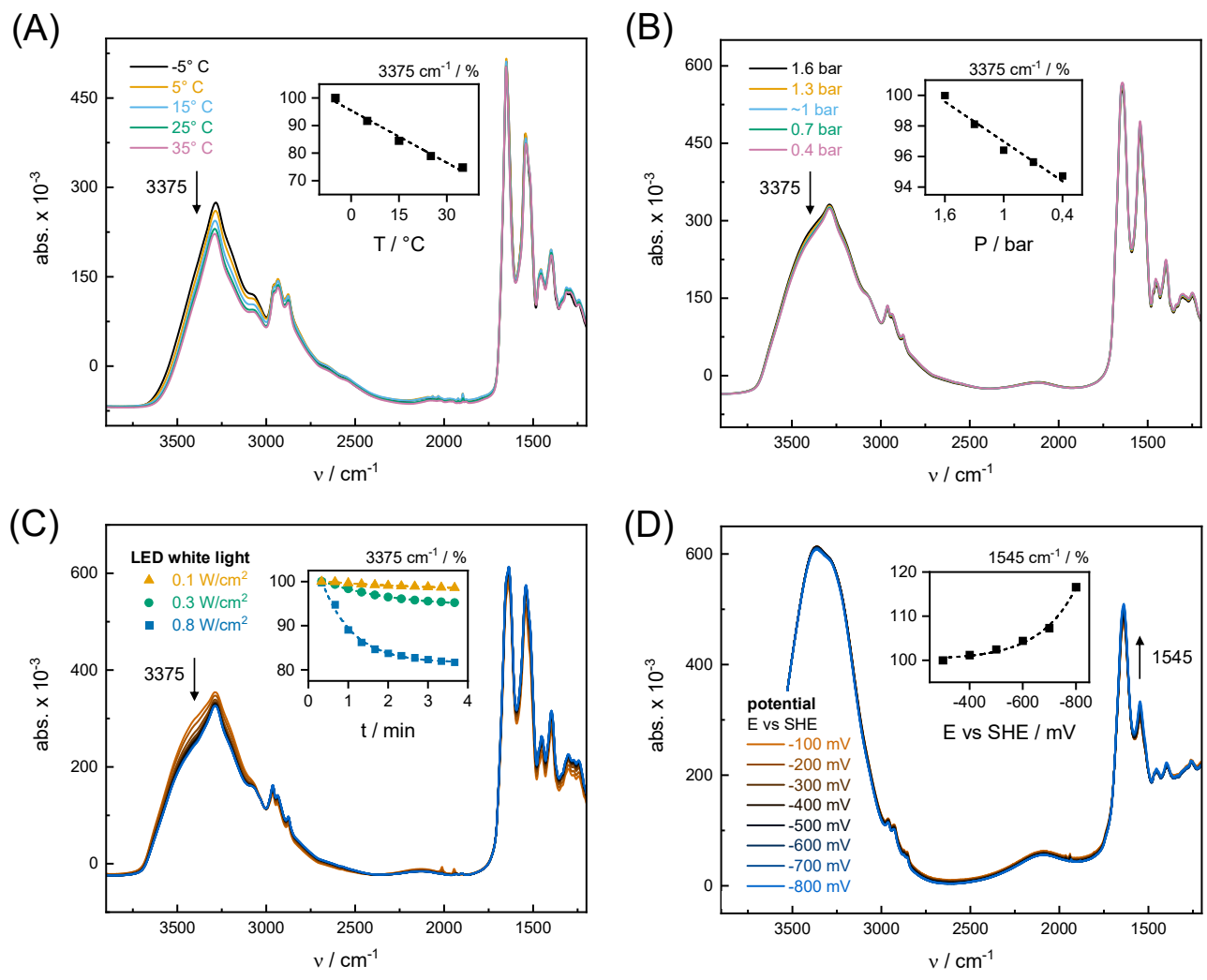

Figure 9 | Influence of temperature, pressure, visible light, and electric potential. (A) Increasing the temperature of the crystal plate from $-5^{\circ}$ to $35^{\circ} \mathrm{C}$ leads to an increasingly dry sample film, as visible from the decrease of water stretching $\left(3375 \mathrm{~cm}^{-1}\right.$, see inset). Example: [FeFe]-hydrogenase TamHydS. (B) Between 1.6 and 0.4 bar, a subtle decrease of humidity is observed towards lower pressure, as illustrated following the water stretching band at $3375 \mathrm{~cm}^{-1}$ (inset). Example: MoFe nitrogenase from $A$. vinelandii. (C) Visible light irradiation. Increasing the relative output power of the LED white light source leads to an increasingly dry sample film, which is explained by collateral heating. The spectra illustrate the effect for a power density of $0.8 \mathrm{~W} / \mathrm{cm}^{-1}$, the inset depicts the decrease of water stretching at $3375 \mathrm{~cm}^{-1}$ over time different power densities. Example: Hmd [Fe]-hydrogenase from M. marburgensis. (D) Electric potential. Increasing the reducing potential from -100 to $-800 \mathrm{mV}$ vs SHE leads to a concentration of protein at the working electrode, as visible from the increase of amide II (1545 $\mathrm{cm}^{-1}$, see inset). Example: [FeFe]hydrogenase $\mathrm{CrHydA}$.

Variations of ambient pressure are known to affect enzymatic performance, structure, and stability. ${ }^{69}$ Figure 9B depicts the changes between 1.6-0.4 bar (equivalent 0.6--0.6 atm) at ambient temperatures. 'Over pressure' is adjusted via the flow controllers (Figure 4) whereas an external vacuum pump can be employed to achieve 'under pressure', e.g., down to 100 mbar. ${ }^{70}$ While the influence on hydration level and protein concentration is less pronounced than for changes in temperature, an approximately linear correlation between pressure and humidity is observed here as well (inset). Low pressure results in dryer films, presumably related to the pressure-depend equilibrium between liquid and gaseous water. No protein structural changes are observed in the investigated pressure regime.

Illumination with a LED light source attached to the titration cell (Figure 4) leads to a notable dehydration of the sample film within minutes. Figure $9 \mathrm{C}$ depicts the effect at an output power of $800 \mathrm{~mW} / \mathrm{cm}^{2}$ white 
light fed to the ATR cell via a wave guide $(\mathrm{d}=1 \mathrm{~cm}, \mathrm{I}=100 \mathrm{~cm})$. The same experiment was performed with $15 \%$ and $5 \%$ output power resulting in significantly more stable films (inset). Whether this effect stems from direct heating (thermal radiation) or light-heat conversion in the protein film is currently unclear; however, facilitating measurements with a minimum of unspecific changes, thorough temperature control, high power densities (i.e., laser irradiation), or efficient absorbers are recommended (Section 5). ${ }^{71}$ Combining ATR FTIR spectroscopy with UV/visible or Resonance Raman spectroscopy (as discussed in the Outlook), both unspecific changes and the electronic excitation of sample may influence the observables. Here, ATR FTIR spectroscopy can serve as a 'dark reference'.

When the protein is in contact with electrolyte buffer and a working electrode (e.g., a gold mesh attached to the ATR crystal plate, see Figure 5B), the influence of electrical fields can be investigated. In comparison to panels $A-C$, Figure 9D reveals that the sample film contains notably more solvent, which confirms contact with the electrolyte. Still, the amide II band at $1545 \mathrm{~cm}^{-1}$ is clearly visible. Increasing the potential across the film stepwise towards negative, 'reducing' values induces microscopic changes between solvent and protein. This leads to a net-increase of protein concentration in the region of the evanescent wave. ${ }^{56}$ Pursuing potential-jump experiments, e.g., to generate difference spectra, such effects must be taken into consideration.

\section{Probing the Reactivity with Gas}

In variance to FTIR spectroscopic investigations on redox enzymes or chromoproteins ${ }^{51-53}$, probing the reactivity of GPMs towards their gaseous reactants demands atmospheric access to the sample, and using an aerosol is imperative to keep the sample film hydrated and functional. While this is theoretically possible in transmission configuration as well, the intense absorption bands of water gas in the aerosol practically impede gas titrations in the frequency regime of interest. To this end, the ATR configuration is the method of choice. In the first paragraph of this section, I will discuss the reaction of GPMs with CO gas, which allows comparing otherwise vastly different enzymatic systems. In the second paragraph, I will focus on $\mathrm{H}_{2}$ oxidation by hydrogenase and how their complex spectra can be disentangled by operando ATR FTIR spectroscopy.

\section{Reactions with Carbon Monoxide Gas}

The presence of coordinatively unsaturated metal sites explains why many GPMs are easily inhibited by $\mathrm{CO}$. In nitrogenase, the details of $\mathrm{CO}$ inhibition and $\mathrm{CO}$ turnover are only beginning to emerge ${ }^{36}$, but it seems to be clear that the enzyme can bind both bridging and terminal CO ligands (Figure 2). ${ }^{72}$ On the opposite, $\mathrm{CO}$ inhibition is an established phenomenon in $\mathrm{CCO}$ (Figure 3) and related heme proteins ${ }^{73}$ as well as all type of hydrogenases (Figure 1). ${ }^{21}$ For example, in the presence of CO gas, the active-ready Hox state of [FeFe]-hydrogenase with three $\mathrm{CO}$ bands converts into the inhibited Hox-CO state with four $\mathrm{CO}$ bands. ${ }^{70}$ Once this pattern has been identified, the inhibition and reactivation of hydrogenase can be followed as a function of time and $\mathrm{CO}$ gas concentration in the carrier gas. Figure 10A depicts differences in CO inhibition for cofactor variants with an amino-, sulfo-, or propanedithiolate headgroup (adt, sdt, or pdt). ${ }^{74}$ 
(A)

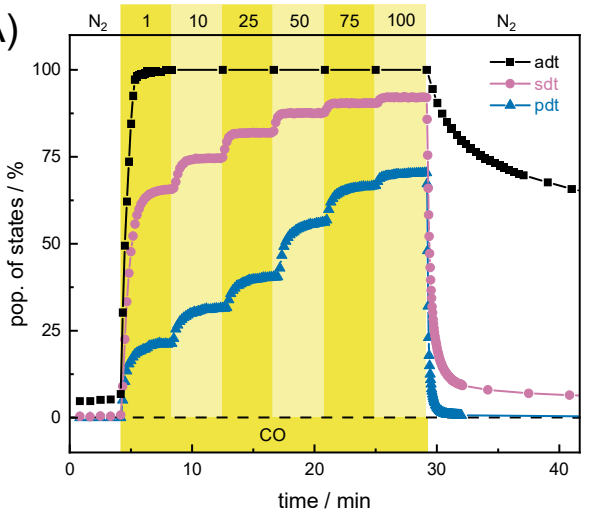

(C)

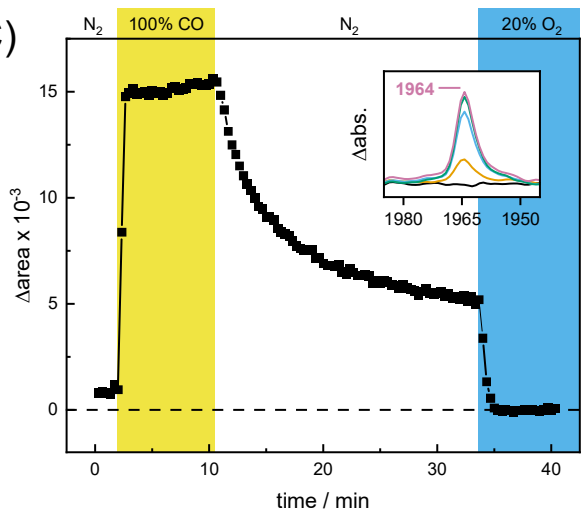

(B)

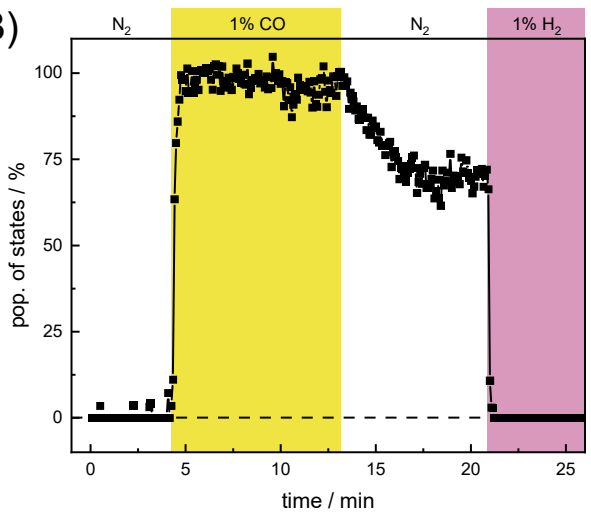

(D)

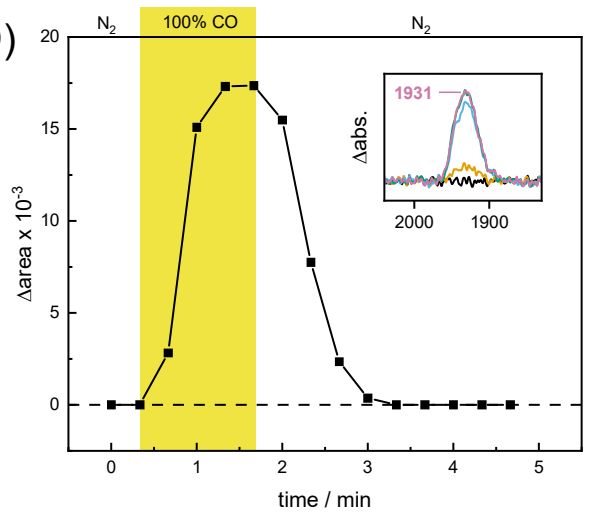

Figure 10 | Reactions with carbon monoxide. (A) In the presence of $0.1-100 \% \mathrm{CO}$, different cofactor variants of the [FeFe]-hydrogenase $\mathrm{CrHydA} 1$ (adt, sdt, pdt) adopt the CO-inhibited state Hox-CO to different extent. The reactivation rates under $\mathrm{N}_{2}$ differ accordingly. (B) In the presence of $1 \% \mathrm{CO}$, the [NiFe]-hydrogenase $E c \mathrm{Hyd}-2$ adopts the $\mathrm{CO}$-inhibited state $\mathrm{Ni}-\mathrm{SCO}$, which largely prevails under $\mathrm{N}_{2}$. Only when the gas atmosphere is exchanged to $\mathrm{H}_{2}$, the enzyme is re-activated completely. (C) The fully reduced CcO from $R$. sphaeroides binds a single terminal CO ligand $\left(1964 \mathrm{~cm}^{-1}\right.$, see inset), which largely prevails under $\mathrm{N}_{2}$. Only when the gas atmosphere is exchanged to $\mathrm{O}_{2}$, the enzyme is oxidized completely. (D) Preincubated with $\mathrm{CO}$ under reducing conditions, the [VFe]-nitrogenase from $A$. vinelandii forms a very stable bridging CO ligand (compare Figure 14D). In variance, the terminal CO ligand (1931 $\mathrm{cm}^{-1}$, see inset) binds rather transient.

Wild-type $\mathrm{CrHydA} 1^{\text {adt }}$ adopts $100 \% \mathrm{Hox}-\mathrm{CO}$ already in the presence of $0.1 \% \mathrm{CO}$ gas where only $65 \%$ and $20 \%$ Hox-CO is observed for $\mathrm{CrHydA} 1^{\text {sdt }}$ and $\mathrm{CrHydA} 1^{\text {pdt }}$, respectively. We explained these difference by diminished stabilization of Hox-CO due a lack of hydrogen-bonding in the modified H-clusters. ${ }^{75}$ [NiFe]hydrogenase is inhibited by CO-binding to the $\mathrm{Ni}$ ion ${ }^{76}$, which is reflected in the characteristic IR pattern of $\mathrm{Ni}-\mathrm{SCO}$ with three $\mathrm{CO}$ bands instead of two. ${ }^{77}$ Figure 10B illustrates the rapid formation of Ni-SCO in the presence of $1 \% \mathrm{CO}$ gas and the comparatively slow reaction under $\mathrm{N}_{2}$. In variance to [FeFe]hydrogenase, $\mathrm{CO}$ binds much weaker to the $\mathrm{Ni}$ ion so that [NiFe]-hydrogenase is easily reactivated in the presence of $1 \% \mathrm{H}_{2}{ }^{78}$

Cytochrome c oxidase is inhibited by $\mathrm{CO}$ in the reduced states MV and FR. Under steady state conditions, $\mathrm{CO}$ binds to the central iron ion of heme $\mathrm{a}_{3}$ from where it may migrate to $\mathrm{Cu}_{\mathrm{B}}$, i.e., upon irradiation with visible light. ${ }^{79}$ The IR bands of Fe-CO $\left(1964 \mathrm{~cm}^{-1}\right)$ and Cu-CO $\left(2045 \mathrm{~cm}^{-1}\right)$ are clearly different. Due to redox 
cooperativity, oxidation of heme a in the MV state causes a $4 \mathrm{~cm}^{-1}$ upshift of the Fe-CO frequency at heme $\mathrm{a}_{3} .^{80}$ This illustrates how $\mathrm{CO}$ ligands report on changes in redox and protonation state through space acting as Stark probes. ${ }^{81}$ Figure $10 \mathrm{C}$ shows rapid binding of $\mathrm{CO}$ to $\mathrm{CcO}$ in the FR state and a slow release under $\mathrm{N}_{2}$. Competition with the natural reactant $\mathrm{O}_{2}$ leads to an immediate reactivation, oxidation, and loss of the CO ligand.

In variance to the other GPMs discussed here, nitrogenase coordinates terminal CO ligands only weakly, at least under mildly reducing conditions, i.e., in the presence of dithionite or the Fe protein and ATP. Figure 10D illustrates the reaction of dithionite-reduced VFe nitrogenase with CO. Inhibition gives rise to a single, broad IR band at $1931 \mathrm{~cm}^{-1}$ (inset) that immediately vanishes in the absence of exogenous CO. As demonstrated by XRD earlier, a $\mu \mathrm{CO}$ ligands can be assumed (Section 6). ${ }^{72}$

\section{Reactions with Hydrogen Gas}

In Section 1, the active site cofactors of [NiFe]- and [FeFe]-hydrogenases are introduced. Their intrinsic $\mathrm{CO}$ and $\mathrm{CN}^{-}$ligands give rise to IR absorbance patterns characteristic for cofactor states like Hox, Hox-CO, and Ni-SCO as discussed above. These patterns can be analysed by FTIR spectroscopy to understand subtle changes in electron density distribution and cofactor geometry, which becomes increasingly important when the catalytically relevant, reduced cofactor states are addressed. For example, at ambient temperature and physiological $\mathrm{pH}$ values, the [FeFe]-hydrogenase $\mathrm{CrHydA} 1$ accumulates two $1 \mathrm{e}^{-}$-reduced (Hred, Hred') and two 2e--reduced H-cluster intermediates (Hsred, Hhyd) under $\mathrm{H}_{2}{ }^{75}$ Figure 11A depicts the conversion of Hox into these intermediates as a function of time and $\mathrm{H}_{2}$ concentration. Between 0.1 $-3 \% \mathrm{H}_{2}$, Hred and Hred' prevail whereas for $\left[\mathrm{H}_{2}\right]>10 \%$ the spectra are increasingly dominated by the 'super-reduced' state, Hsred. The so-called 'hydride state' (Hhyd, green trace) typically remains below $10 \%$ at physiological $\mathrm{pH}$ values. ${ }^{82}$ When the atmosphere is switched back to $\mathrm{N}_{2}$ Hsred and Hhyd decay transiently into Hred and Hred' before the enzyme converts back into the oxidized state ('auto-oxidation' due to proton reduction and $\mathrm{H}_{2}$ release). Figure 11B shows a difference spectrum between $\mathrm{N}_{2}$ and $10 \%$ $\mathrm{H}_{2}$ (triangles in panel A) that conveys an idea of the spectral complexity. The cofactor bands of Hox are negative, the overlapping band patterns of Hred', Hred, and Hsred (five bands each) are positive. In Section 5, we will see how potential-jump experiments at different $\mathrm{pH}$ values can be used to disentangle the crowded IR spectra of [FeFe]-hydrogenase under reducing conditions. 

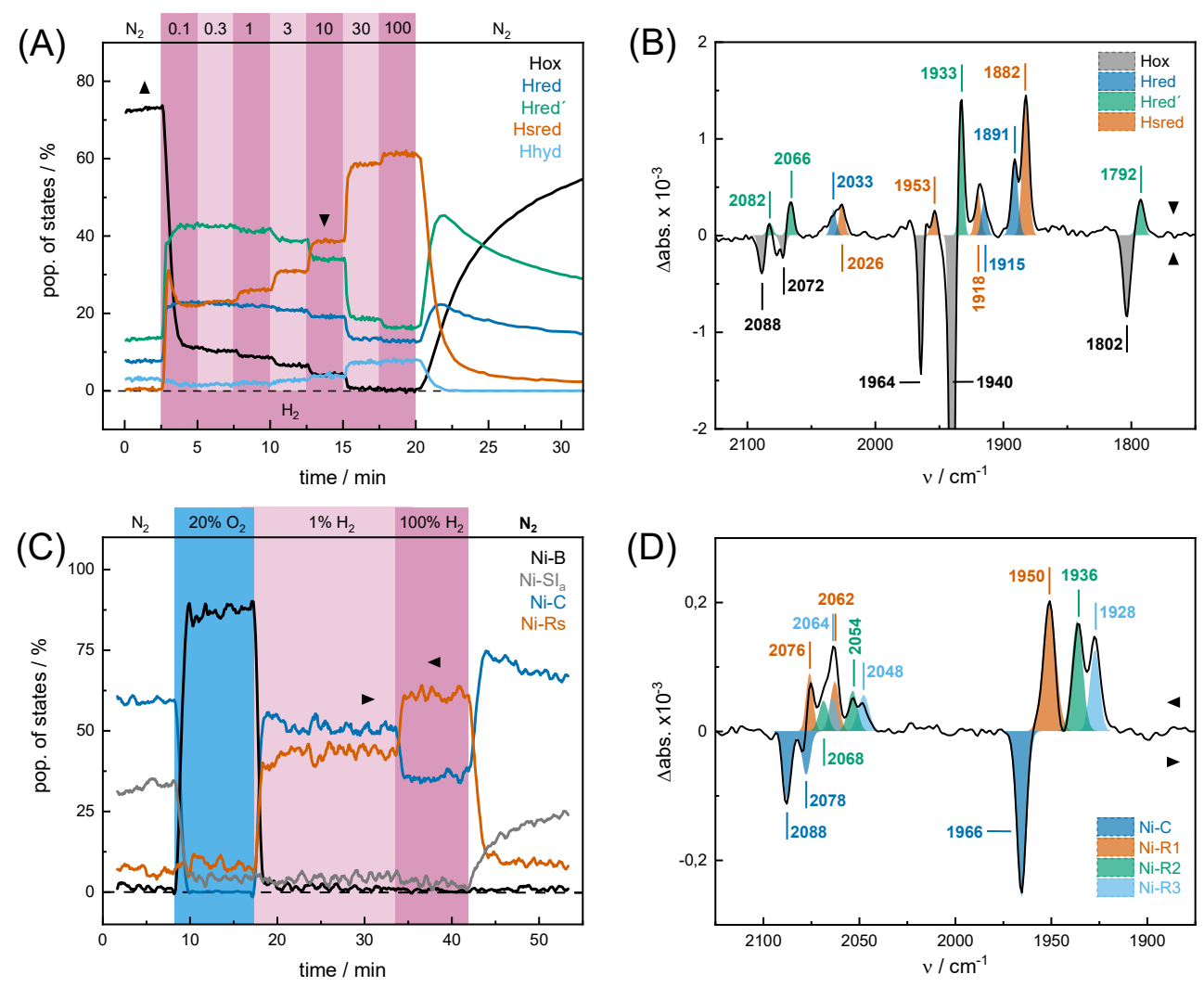

Figure 11 | Reactions with $\mathbf{H}_{2}$. (A) In the presence of $0.1-100 \% \mathrm{H}_{2}$, the [FeFe]-hydrogenase $\mathrm{CrHydA} 1$ adopts a variety of reduced cofactor states $(\mathrm{pH} 8)$. For $\left[\mathrm{H}_{2}\right]>10 \%, 2 \mathrm{e}^{-}$-reduced states (Hsred, Hhyd) prevail. When the gas atmosphere is switched back to $\mathrm{N}_{2}$, a transient increase of $1 \mathrm{e}^{-}$-reduced states (Hred, Hred') is observed before the system converges into the oxidized state, Hox. (B) ' $10 \% \mathrm{H}_{2}-\mathrm{N}_{2}$ ' difference spectrum in the $\mathrm{CO} / \mathrm{CN}^{-}$regime of the Fe-Fe cofactor at the points indicated in panel $\mathrm{A}(\boldsymbol{\Delta} / \boldsymbol{\nabla})$. Reduced states appear as positive bands. (C) In the presence of $\sim 20 \% \mathrm{O}_{2}$, the [NiFe]-hydrogenase EcHyd-2 adopts the inactive state $\mathrm{Ni}-\mathrm{B}$ at the expense of resting states $\mathrm{Ni}-\mathrm{SI}$ and $\mathrm{Ni}-\mathrm{SI}$. The enzyme is immediately activated at $1 \% \mathrm{H}_{2}$, forming $\mathrm{Ni}-\mathrm{C}$ and a mixture of three different $\mathrm{Ni}-\mathrm{R}$ states, the latter that increases further over $\mathrm{Ni}-\mathrm{C}$ under $100 \% \mathrm{H}_{2}$. When the gas atmosphere is switched back to $\mathrm{N}_{2}$, a transient increase of $\mathrm{Ni}-\mathrm{C}$ is observed before the system slowly converges into Ni-SI. (D) ' $100 \% \mathrm{H}_{2}-1 \% \mathrm{H}_{2}$ ' difference spectrum in the $\mathrm{CO} / \mathrm{CN}^{-}$regime of the Ni-Fe cofactor at the points indicated in panel $\mathrm{C}(\mathbf{D} / \mathbf{4})$. The spectrum shows the different $\mathrm{Ni}-\mathrm{R}$ states (positive bands) and the $\mathrm{Ni}-\mathrm{C}$ state (negative bands).

[NiFe]-hydrogenases display a comparable variety of reduced states. ${ }^{83}$ Upon oxidation of $\mathrm{H}_{2}$, the cofactor adopts a geometry with a Ni-Fe bridging hydride ligand $(\mu \mathrm{H})$ in the $2 \mathrm{e}^{-}$-reduced state $\mathrm{Ni}-\mathrm{R}$ and the $1 \mathrm{e}^{-}-$ reduced state $\mathrm{Ni}-\mathrm{C} .{ }^{84} \mathrm{Ni}-\mathrm{L}$ resembles $\mathrm{Ni}-\mathrm{C}$ in terms of electron count but does not bind a $\mu \mathrm{H}$ ligand. Both $\mathrm{Ni}-\mathrm{L}$ and $\mathrm{Ni}-\mathrm{R}$ exist in three variations, presumably reflecting difference in protonation state. ${ }^{85}$ Figure $11 \mathrm{C}$ depicts the reaction of [NiFe]-hydrogenase $E c \mathrm{Hyd}-2$ with $\mathrm{O}_{2}$, which converts the enzyme very efficiently into the $\mathrm{O}_{2}$-inhibited state $\mathrm{Ni}-\mathrm{B} .{ }^{78}$ In the presence of $1 \% \mathrm{H}_{2}$, the enzyme is immediately reactivated adopting a mixture of $\mathrm{Ni}-\mathrm{C}$ and $\mathrm{Ni}-\mathrm{R}$. In fact, $\mathrm{Ni}-\mathrm{R}$ consists of $\mathrm{R} 1, \mathrm{R} 2$, and $\mathrm{R} 3$ that are combined into a single trace to simplify the panel. Similar to what has been observed for [FeFe]-hydrogenase, higher concentrations of $\mathrm{H}_{2}$ promote an accumulation of $2 \mathrm{e}^{-}$-reduced states (here: $\mathrm{Ni}-\mathrm{R}$ ). In the absence of $\mathrm{H}_{2}$, $\mathrm{Ni}-\mathrm{C}$ and the oxidized $\mathrm{Ni}_{-} \mathrm{Sl}_{\mathrm{a}}$ state increase over $\mathrm{Ni}-\mathrm{R}$. Figure 11D shows a difference spectrum between 
$1 \% \mathrm{H}_{2}$ and $100 \% \mathrm{H}_{2}$ (asterisks in panel D) that allows identifying Ni-R1 - R3 due to the lack of changes related to $\mathrm{Ni}-\mathrm{Sl} \mathrm{a}_{a}$ and $\mathrm{Ni}-\mathrm{B}$. Note that the $1 \mathrm{e}^{-}$-reduced state $\mathrm{Ni}-\mathrm{L}$ is not observed. This cofactor intermediate has been accumulated upon visible light irradiation at cryogenic temperatures. ${ }^{86}$ Similar operando approaches are discussed in the next section.

\section{Complementary Operando Approaches}

The susceptibility of metal carbonyl complexes to light inactivation can be exploited to photolyze CO and hydride ligands, e.g., in bimetallic hydrogenases ${ }^{86-88}$ or cytochrome c oxidase. ${ }^{79}$ In [Fe]-hydrogenase, illumination leads to a significant and irreversible loss of activity following an unknown molecular mechanism. ${ }^{89}$ Operando ATR FTIR spectroscopy may help understanding the underlying principles. The spectra in Figure 12A show the vibrationally coupled CO bands of the Fe-GMP cofactor ${ }^{21}$ recorded under $\mathrm{N}_{2}$, in the presence of $\mathrm{H}_{4} \mathrm{MPT}$, and in the dark. Illumination with white light $\left(0.8 \mathrm{~W} / \mathrm{cm}^{2}\right.$, same dataset as in Figure 9C) induces a mean band shift of $\Delta 60 \mathrm{~cm}^{-1}$ towards lower energies indicative of photoreduction. Moreover, Figure 12A hints at processes that are easily overlooked in steady-state experiments. For example, the inset highlights the immediate and transient increase of a small band at $2069 \mathrm{~cm}^{-1}$ whose origin is unclear but may be related to a short-lived accumulation of the CO-inhibited state of the Fe-GP cofactor. $^{21}$ In [FeFe]-hydrogenase, 'cannibalization' upon illumination is a frequently observed phenomen ${ }^{90}$ and the overall loss of $\sim 70 \%$ signal intensity suggests significant damage to the Fe-GP cofactor, indeed. In the presence of $\mathrm{CO}$ gas, light-induced inactivation of [Fe]-hydrogenase was found to be diminished ${ }^{89}$, supporting the theory of $\mathrm{CO}$ liberation under illumination conditions.
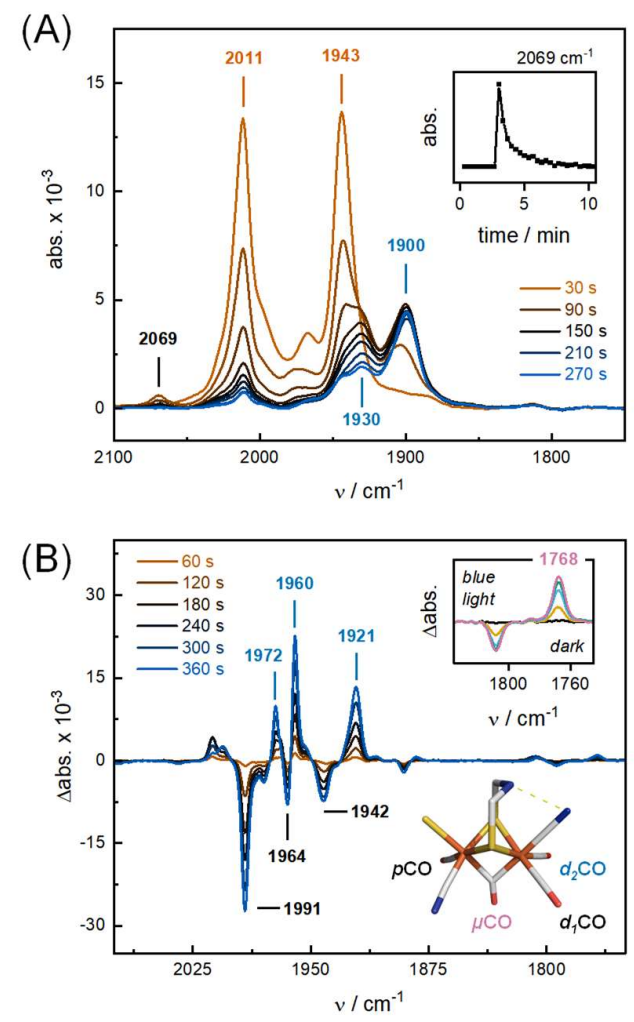

Figure 12 | Light-triggered reactions. (A) Upon irradiation with white light, the Fe-GP cofactor of the [Fe]hydrogenase from M. marburgensis is partly degraded. The cofactor with CO bands at 2011 and $1943 \mathrm{~cm}^{-}$ ${ }^{1}$ converges towards a species with CO bands at 1930 and $1900 \mathrm{~cm}^{-1}$. Note the transient population of a 
small band at $2069 \mathrm{~cm}^{-1}$ (inset). (B) Site-selective ${ }^{13} \mathrm{CO}$ isotope editing of the cofactor in [FeFe]hydrogenases $\mathrm{CrHydA1}$. The difference spectrum depicts the conversion of $\mathrm{Hox}-{ }^{13} \mathrm{CO}$ into $\mathrm{Hox}-\left({ }^{13} \mathrm{CO}\right)_{2}$ upon irradiation with red light. When switched the blue light, the bridging ${ }^{12} \mathrm{CO}$ ligand exchanges to ${ }^{13} \mathrm{CO}$ (inset). The model shows the geometry of the CO-inhibited diiron site.

Inhibition with $\mathrm{CO}$ also protects [FeFe]-hydrogenase from light inactivation and facilitates ${ }^{12} \mathrm{CO} /{ }^{13} \mathrm{CO}$ isotope editing. ${ }^{90}$ Crucially, we found that different light qualities allow exchanging the $\mathrm{CO}$ ligands oneby-one. Figure 12B depicts a 'light - dark' difference spectrum obtained in the presence of $1 \mathrm{~atm}{ }^{13} \mathrm{CO}$ gas and red-light illumination $(640 \mathrm{~nm})$. The dark state, Hox ${ }^{13} \mathrm{CO}$, carries a single ${ }^{13} \mathrm{CO}$ ligand at position $\mathrm{d}_{1}$ and appears with negative bands in the spectrum, whereas $\mathrm{Hox}-\left({ }^{13} \mathrm{CO}\right)_{2}$ was computed to bind two ${ }^{13} \mathrm{CO}$ ligands (at $d_{1}$ and $d_{2}$ ). ${ }^{70}$ Note the lack of significant changes in the $\mu \mathrm{CO}$ regime; only when illuminated at $460 \mathrm{~nm}$, quantitative isotope editing of the $\mu \mathrm{CO}$ ligand is observed (inset). The need for blue light irradiation illustrates the stability of the $\mu \mathrm{CO}$ ligand relative to the terminal ligands. The frequency of the $\mathrm{CN}^{-}$ligands is barely affected by $\mathrm{CO}$ isotope editing. ${ }^{70}$

Site-selective isotope editing was instrumental in the assignment of individual bands in the reduced $\mathrm{H}$ cluster states Hred', Hred, and Hsred. ${ }^{63,91}$ However, the crowded spectra observed in the presence of $\mathrm{H}_{2}$ remain a notable spectroscopic challenge. Both $1 \mathrm{e}^{-}$-reduced states Hred' and Hred are formed upon proton-coupled electron transfer and can be distinguished in FTIR spectro-electrochemistry due to their different $p \mathrm{~K}_{\mathrm{a}}$ values. ${ }^{92}$ Figure 13 compare two difference spectra recorded in potential-jump experiments at (a) $\mathrm{pH} 9$ and (b) $\mathrm{pH} \mathrm{5.93}$ Under alkaline conditions and reducing potentials (-650 mV vs SHE), Hox converts exclusively into Hred'. On the opposite, Hred converts exclusively into Hsred under acidic conditions and strongly reducing potentials (-750 $\mathrm{mV}$ vs SHE). In both spectra the small downshifts reflect a reduction of the $[4 \mathrm{Fe}-4 \mathrm{~S}]$-cluster, which facilitates a unique band assignment.

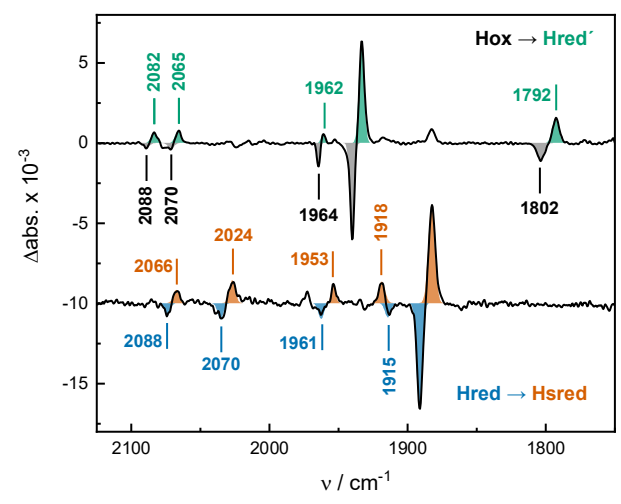

Figure 13 | Potential-triggered reactions. ATR FTIR spectro-electrochemistry allows recording potentialjump difference spectra, e.g., of the [FeFe]-hydrogenase $\mathrm{CrHydA1}$. The upper spectrum shows the accumulation of Hred' (-650 mV, main band $\left.1933 \mathrm{~cm}^{-1}\right)$ over Hox $\left(-450 \mathrm{mV}\right.$, main band $\left.1940 \mathrm{~cm}^{-1}\right)$ at pH 9 whereas the lower spectrum shows the accumulation of Hsred $\left(-750 \mathrm{mV}\right.$, main band $\left.1882 \mathrm{~cm}^{-1}\right)$ over Hred $\left(-550 \mathrm{mV}\right.$, main band $\left.1890 \mathrm{~cm}^{-1}\right)$ at $\mathrm{pH}$ 5. The small shift to lower wavenumbers in both spectra has been assigned to a reduction of the [4Fe-4S] cluster. 
Note that temperature seems to affect the geometry of the reduced $\mathrm{H}$-cluster: under cryogenic conditions, intermediates of Hred and Hsred have been identified that carry a $\mu \mathrm{CO}$ ligand, ${ }^{87,94}$ which happens to be different at ambient temperature. For example, in the 'Hsred - Hred' difference spectrum in Figure 13 no CO ligands are observed at frequencies smaller $1880 \mathrm{~cm}^{-1}$. The underlying principles are not understood yet ${ }^{14}$ but an XAS analysis of metal-ligand bond distances suggests that certain motions are precluded below $200 \mathrm{~K} .{ }^{95}$ This can involve the release of the $\mu \mathrm{CO}$ ligand into a terminal position and the formation of a bridging hydride ligand, as proposed earlier. ${ }^{91}$

\section{Expanding the Spectral Window}

The analysis of infrared bands between $2600-1800 \mathrm{~cm}^{-1}$ can be performed on absolute spectra and typically provides meaningful data even if the protein film is not perfectly stable. Other regimes are only available in difference mode (Figure 4); however, the trigger concepts discussed in Section 4 and Section $\mathbf{5}$ often induce unspecific changes in hydration level and protein concentration. This usually impedes any meaning full analysis of smaller signals in difference spectra. To expand the spectral window towards energies lower than $1800 \mathrm{~cm}^{-1}$, highly specific trigger protocols must be devised.

[FeFe]-hydrogenase reacts with visible light in various ways. Under cryogenic conditions, a reduction of the [4Fe-4S] cluster has been observed, ${ }^{96}$ and when the reduced diiron site was illuminated two Hhyd-like $\mathrm{H}$-cluster states were trapped. ${ }^{87}$ Under ambient conditions, visible light has been exploited in XRD flashphotolysis experiments ${ }^{97}$ and $\mathrm{CO}$ isotope editing (Figure 12). ${ }^{70}$ Moreover, various attempts to lightinduced $\mathrm{H}_{2}$ production are documented, e.g., coupling [FeFe]-hydrogenase with chromoproteins or redox dyes. ${ }^{98-100}$ We found that carboxy-terminated eosin Y (5CE) and zinc tetraphenylporphyrin (ZnTPPS) can be used to efficiently trigger the transition of oxidized protein into Hred or Hred'. The reduction of the diiron site is coupled to catalytic proton transfer. Therefore, investigating 'Hred - Hox' difference spectra conveyed a dynamic understanding of the hydrogen-bonding changes that facilitate proton transfer (Figure 14A). ${ }^{71}$ The respective changes in the frequency regime below $1800 \mathrm{~cm}^{-1}$ for [FeFe]-hydrogenase $\mathrm{CrHydA} 1$ are shown in Figure 14B. Negative bands belong to Hox (note the large $\mu \mathrm{CO}$ band at $1802 \mathrm{~cm}^{-1}$ in the main panel), positive bands belong to Hred. The $\Delta 6 \mathrm{~cm}^{-1}$ downshift of the difference feature between 1715 and $1700 \mathrm{~cm}^{-1}$ in $\mathrm{D}_{2} \mathrm{O}$ suggests an assignment to glutamic acid residue E141. Moreover, the $\Delta 75 \mathrm{~cm}^{-1}$ downshift from 1680 to $1605 \mathrm{~cm}^{-1}$ in $\mathrm{D}_{2} \mathrm{O}$ can be assigned to a deprotonation of arginine R148. ${ }^{71}$

In the SH frequency regime around $2500 \mathrm{~cm}^{-1}$ (compare Figure 4) any difference signals are missing. This makes protonation or hydrogen-bonding changes involving the cysteine residue C169 in the proton transfer pathway rather unlikely. In [NiFe]-hydrogenase such signals were clearly visible. ${ }^{101}$ Investigating 'Hred' - Hox' and 'Hox-CO - Hox' difference spectra does not hint at significant hydrogen-bonding changes. Moreover, a basically featureless difference spectrum is observed ${ }^{71}$ when $\mathrm{CrHydA} 1$ apo-protein is illuminated in the presence of $5 \mathrm{CE}$, which proves that all changes in Figure 14B stem from functional enzyme. 
(A)

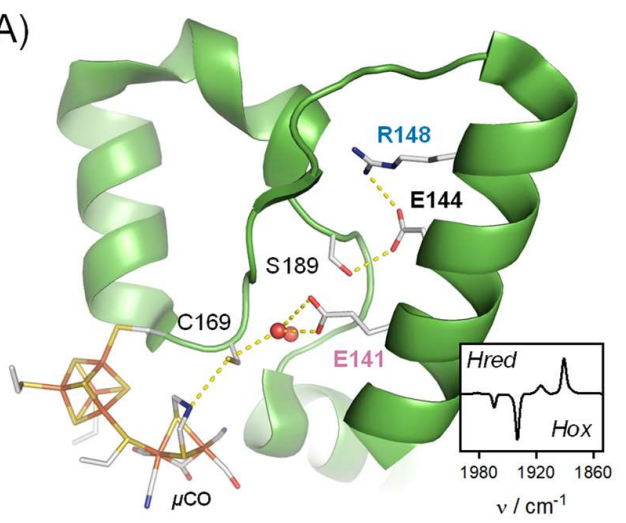

(C)

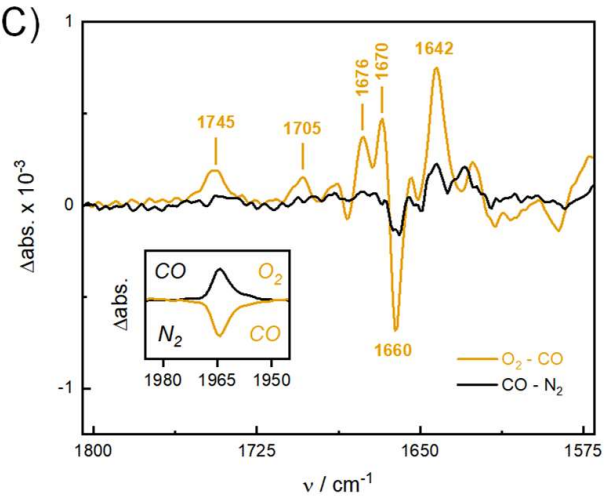

(B)

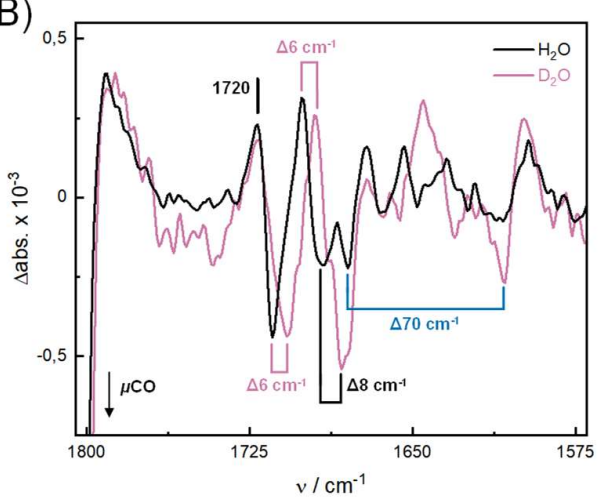

(D)

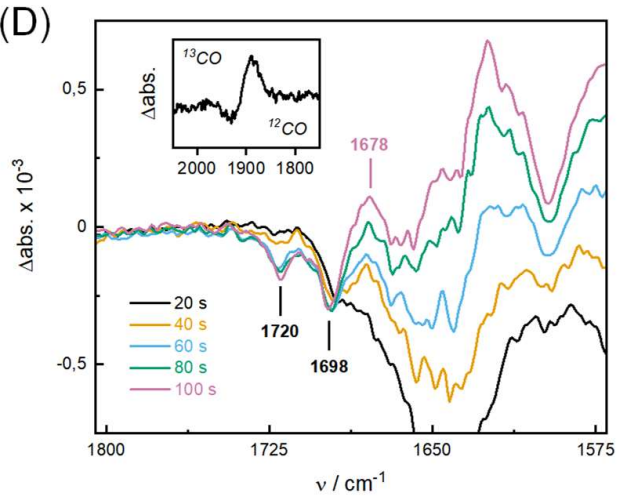

Figure 14 I Investigating the IR regime below $1800 \mathrm{~cm}^{-1}$. (A) Proton transfer pathway in [FeFe]hydrogenase $\mathrm{CrHydA} 1$. In the presence of a redox dye, illumination allows accumulating Hred over Hox (inset). (B) 'Hred - Hox' difference spectra between $1800-1575 \mathrm{~cm}^{-1}$. The observed H/D shifts to smaller energy facilitate an assignment to glutamic acid residues E141 (magenta labels) and E144 (black labels) as well as arginine R148 (blue labels). (C) 'CO $-\mathrm{N}_{2}$ ' and ' $\mathrm{O}_{2}-\mathrm{CO}^{\prime}$ difference spectra of $\mathrm{CcO}$ from $R$. sphaeroides (black and orange traces, respectively). The right inset shows the CO band at $1964 \mathrm{~cm}^{-1}$ confirming the FR state. Upon oxidation, positive bands at 1745 and $1705 \mathrm{~cm}^{-1}$ are observed alongside prominent signals at $1676,1670,1660$, and $1642 \mathrm{~cm}^{-1}$. (D) ' ${ }^{13} \mathrm{CO}-{ }^{12} \mathrm{CO}^{\prime}$ difference spectrum of the VFe nitrogenase from $A$. vinelandii recorded at 1.5 bar pressure. While the temporal progression of spectra shows changes in the amide regime $<1650 \mathrm{~cm}^{-1}$, the data allows assigning two negative $\mu^{12} \mathrm{CO}$ signals and at least one positive $\mu^{13} \mathrm{CO}$ band $\left(1678 \mathrm{~cm}^{-1}\right.$, magenta label). The inset depicts the conversion of the terminal ${ }^{12} \mathrm{CO}$ ligand from $1931 \mathrm{~cm}^{-1}$ (negative) to $1888 \mathrm{~cm}^{-1}\left({ }^{13} \mathrm{CO}\right.$, positive).

It is demonstrated at the example of $\mathrm{CcO}$ that gas titrations can serve as a trigger generating stable IR difference spectra. The inset of Figure $14 \mathrm{C}$ depicts the reaction of dithionite-reduced $\mathrm{CcO}$ with $\mathrm{CO}$ and $\mathrm{O}_{2}$, subsequently (same data set as in Figure 10C). In the first step, CO binds to the fully reduced BNC (1964 $\mathrm{cm}^{-1}$ ). The respective 'CO $-\mathrm{N}_{2}$ ' difference spectrum below $1800 \mathrm{~cm}^{-1}$ is featureless (black, in the main panel), suggesting only a minimum of unspecific changes in the protein film. However, upon contact with $\mathrm{O}_{2}$ the $\mathrm{CO}$ band is lost immediately (inset), indicating replacement of $\mathrm{CO}$ and/or oxidation of the $\mathrm{BNC}$. The ' $\mathrm{O}_{2}-\mathrm{CO}^{\prime}$ difference spectrum in the main panel shows a characteristic difference signature (blue). Although some of these bands have been assigned ${ }^{102-106}$, a comprehensive understanding of all observed differences, including hydrogen-bonding and protonation changes as well as protein structural and hemeassociated changes is yet to achieve. 
Inhibition of nitrogenase with $\mathrm{CO}$ has been used to identify hydride binding sites that may play a role in $\mathrm{N}_{2}$ fixation or the CO reduction reaction. ${ }^{3}$ Depending on the reductant FTIR and EPR spectroscopy suggested both Fe-terminal and Fe-Fe bridging ligands, ${ }^{34,107,108}$ typically employing illumination protocols. ${ }^{109}$ As shown in Figure 10, gas titrations demonstrate the coordination of a terminal CO ligand in dithionite-reduced VFe nitrogenase pre-incubated with $\mathrm{CO}$ gas. Exchanging the atmosphere from ${ }^{12} \mathrm{CO}$ to ${ }^{13} \mathrm{CO}$, an isotopic shift from 1931 to $1888 \mathrm{~cm}^{-1}$ is observed (Figure 14D, inset) that confirms the presence of a terminal $\mathrm{CO}$. While the respective ${ }^{13} \mathrm{CO}-{ }^{12} \mathrm{CO}^{\prime}$ difference spectrum is not without unspecific changes, it clearly comprises of two negative bands at 1720 and $1698 \mathrm{~cm}^{-1}$. In the MoFe nitrogenase from $A$. vinelandii, very similar bands were assigned to $\mu \mathrm{CO}$ species at varying $\mathrm{CO}$ pressure. ${ }^{107}$ The positive feature at $1678 \mathrm{~cm}^{-1}$ may represent a $\mu^{13} \mathrm{CO}$ ligand.

\section{Outlook}

Operando ATR FTIR spectroscopy is a versatile and powerful technique for the analysis of metalloenzymes and GPMs in particular. Due to the electronically non-invasive absorption of infrared radiation, the technique can be applied under biologically relevant conditions, which makes it compatible with many biochemical or electrochemical assays. Moreover, the low sample demand qualifies ATR FTIR spectroscopy for high-throughput approaches or the measurement of rare sample. Absolute FTIR absorbance spectra grant immediate access to information about film hydration (or deuteration), protein and reactant concentration, as well as the cofactor state (i.e., via ligands like $\mathrm{CO}$ or $\mathrm{CN}^{-}$). However, analysing bands of low absorbance or overlapping signals, efficient trigger concept must be devised to compute accurate FTIR difference spectra. ${ }^{49}$ Besides illumination, solvent exchange, and potential jump experiments ${ }^{59-61}$, I introduced quantitative gas titrations as a novel trigger strategy.

While this perspective is focused on hydrogenase, nitrogenase, and cytochrome c oxidase, there are numerous other GPMs that can be analysed by operando ATR FTIR spectroscopy under gas control. This may include the metalloenzymes of $\mathrm{CO}_{2}$ turnover, for example $\mathrm{CO}$ dehydrogenase (CODH) and formate hydrogenase $(\mathrm{FDH}) .{ }^{110}$ The Fe protein of nitrogenase has been suggested to catalyse $\mathrm{CO}_{2}$ reduction as well ${ }^{38}$, and a similar reactivity was proposed for $\mathrm{HypD}$, an iron-sulphur enzyme of the [NiFe]-hydrogenase maturation machinery. ${ }^{111}$ The membrane protein NO reductase (NOR) is another example of an interesting GPM. ${ }^{112}$ As a heme copper oxidase, NOR is closely related to $\mathrm{CcO}$ but catalyses the reduction of nitric oxide into nitrous oxide $\left(\mathrm{N}_{2} \mathrm{O}\right)$ and water. ${ }^{113}$

Currently, we are developing an experimental setup to combine ATR FTIR spectroscopy with resonance Raman (RR) spectroscopy. The silicon crystal of the ATR unit does not only serve as an excellent reference for Raman scattering but can be exploiting to record UV/vis reflection spectra or fluorescence emission as well. Simultaneous FTIR/RR or FTIR/UV/vis experiments will be combined with gas- or potential control, as detailed in Section 2. These developments will facilitate a holistic understanding of small molecule activation with gas-processing metalloenzymes.

\section{Conflicts of interest}

There are no conflicts to declare.

\section{Acknowledgements}

I am thankful for the generous supply of protein from various groups. This includes [FeFe]-hydrogenase from Thomas Happe (Bochum) and Gustav Berggren (Uppsala), [NiFe]-hydrogenase from Basem Soboh (Berlin), Hmd [Fe]-hydrogenase from Siego Shima (Marburg), MoFe and VFe nitrogenase from Oliver Einsle (Freiburg), and Cytochrome c oxidase from Ramona Schlesinger (Berlin). I would like to 
acknowledge Moritz Senger, Konstantin Laun, Federico Baserga, Emanuel Pfitzner, and Michael Haumann for many hours at the spectrometer, in the workshop, and around coffee cups. In pandemic times, these are valuable memories. Finally, let me thank Joachim Heberle for his ongoing support and counsel. The Deutsche Forschungsgemeinschaft (DFG) funded this research within the framework of priority program 1927 (STR 1554/5-1).

\section{References}

(1) McEvoy, J. P.; Brudvig, G. W. Water-Splitting Chemistry of Photosystem II. Chem. Rev. 2006, 106 (11), 4455-4483. https://doi.org/10.1021/cr0204294.

(2) Yoshikawa, S.; Shimada, A. Reaction Mechanism of Cytochrome c Oxidase. Chem. Rev. 2015, 115 (4), 1936-1989. https://doi.org/10.1021/cr500266a.

(3) Hoffman, B. M.; Lukoyanov, D.; Yang, Z.; Dean, D. R.; Seefeldt, L. C. Mechanism of Nitrogen Fixation by Nitrogenase : The Next Stage. Chem. Rev. 2014, 114 (8), 4041-4062. https://doi.org/10.1021/cr400641x.

(4) Kretsinger, R. H. Calcium-Binding Proteins. Annu. Rev. Biochem. 1976, 45, 239-266.

(5) Cowan, J. A. Metal Activation of Enzymes in Nucleic Acid Biochemistry. Chem. Rev. 1998, 98 (3), 1067-1087. https://doi.org/10.1021/cr960436q.

(6) Vašák, M.; Schnabl, J. Sodium and Potassium lons in Proteins and Enzyme Catalysis. Met. Ions Life Sci. 2016, 16, 259-290. https://doi.org/10.1007/978-3-319-21756-7_8.

(7) Bullock, R. M.; Chen, J. G.; Gagliardi, L.; Chirik, P. J.; Farha, O. K.; Hendon, C. H.; Jones, C. W.; Keith, J. A.; Klosin, J.; Minteer, S. D.; Morris, R. H.; Radosevich, A. T.; Rauchfuss, T. B.; Strotman, N. A.; Vojvodic, A.; Ward, T. R.; Yang, J. Y.; Surendranath, Y. Using Nature's Blueprint to Expand Catalysis with Earth-Abundant Metals. Science (80-. ). 2020, 369, eabc3183. https://doi.org/10.1126/science.eabc3183.

(8) Sapra, R.; Bagramyan, K.; Adams, M. W. W. A Simple Energy-Conserving System: Proton Reduction Coupled to Proton Translocation. Proc. Natl. Acad. Sci. U. S. A. 2003, 100 (13), 7545-7550. https://doi.org/10.1073/pnas.1331436100.

(9) Hemschemeier, A.; Fouchard, S.; Cournac, L.; Peltier, G.; Happe, T. Hydrogen Production by Chlamydomonas Reinhardtii: An Elaborate Interplay of Electron Sources and Sinks. Planta 2008, 227 (2), 397-407. https://doi.org/10.1007/s00425-007-0626-8.

(10) Roberts, G. P.; Youn, H.; Kerby, R. L. CO-Sensing Mechanisms. Microbiol. Mol. Biol. Rev. 2004, 68 (3), 453. https://doi.org/10.1128/MMBR.68.3.453.

(11) Cortese-Krott, M. M.; Kuhnle, G. G. C.; Dyson, A.; Fernandez, B. O.; Grman, M.; DuMond, J. F.; Barrow, M. P.; McLeod, G.; Nakagawa, H.; Ondrias, K.; Nagy, P.; King, S. B.; Saavedra, J. E.; Keefer, L. K.; Singer, M.; Kelm, M.; Butler, A. R.; Feelisch, M. Key Bioactive Reaction Products of the NO/H2S Interaction Are S/N-Hybrid Species, Polysulfides, and Nitroxyl. Proc. Natl. Acad. Sci. U. S. A. 2015, 112 (34), E4651-E4660. https://doi.org/10.1073/pnas.1509277112.

(12) Lubitz, W.; Ogata, H.; Rüdiger, O.; Reijerse, E. Hydrogenases. Chem. Rev. 2014, 114 (8), 4081- 
4148. https://doi.org/10.1021/cr4005814.

(13) Vignais, P. M.; Billoud, B. Occurrence, Classification, and Biological Function of Hydrogenases: An Overview. Chem. Rev. 2007, 107 (10), 4206-4272. https://doi.org/10.1021/cr050196r.

(14) Land, H.; Senger, M.; Berggren, G.; Stripp, S. T. Current State of [FeFe]-Hydrogenase Research Biodiversity and Spectroscopic Investigations. ACS Catal. 2020, 10, 7069-7086. https://doi.org/10.1021/acscatal.0c01614.

(15) Fritsch, J.; Scheerer, P.; Frielingsdorf, S.; Kroschinsky, S.; Friedrich, B.; Lenz, O.; Spahn, C. M. T. The Crystal Structure of an Oxygen-Tolerant Hydrogenase Uncovers a Novel Iron-Sulphur Centre. Nature 2011, 479, 249-252. https://doi.org/10.1038/nature10505.

(16) Huang, G.; Wagner, T.; Ermler, U.; Shima, S. Methanogenesis Involves Direct Hydride Transfer from $\mathrm{H} 2$ to an Organic Substrate. Nat. Rev. Chem. 2020, 4, 213-221. https://doi.org/10.1038/s41570-020-0167-2.

(17) Tai, H.; Hirota, S.; Stripp, S. T. Proton Transfer Mechanisms in Bimetallic Hydrogenases. Acc. Chem. Res. 2020. https://doi.org/10.20944/preprints202007.0034.v1.

(18) Vincent, K. A.; Parkin, A.; Armstrong, F. A. Investigating and Exploiting the Electrocatalytic Properties of Hydrogenases. Chem. Rev. 2007, 107 (10), 4366-4413. https://doi.org/10.1021/cr050191u.

(19) Pierik, A. J.; Hulstein, M.; Hagen, W. R.; Albracht, S. P. J. A Low-Spin Iron with CN and CO as Intrinsic Ligands Forms the Core of the Active Site in [Fe]-Hydrogenases. Eur. J. Biochem. 1998, 258 (2), 572-578.

(20) Pierik, A. J.; Roseboom, W.; Happe, R. P.; Bagley, K. A.; Albracht, P. J. Carbon Monoxide and Cyanide as Intrinsic Ligands to Iron in the Active Site of [NiFe]-Hydrogenases. J. Biol. Chem. 1999, 274 (6), 3331-3337. https://doi.org/10.1074/jbc.274.6.3331.

(21) Lyon, E. J.; Shima, S.; Boecher, R.; Thauer, R. K.; Grevels, F.-W.; Bill, E.; Roseboom, W.; Albracht, S. P. J. Carbon Monoxide as an Intrinsic Ligand to Iron in the Active Site of the Iron-Sulfur-ClusterFree Hydrogenase H2-Forming Methylenetetrahydromethanopterin Dehydrogenase as Revealed by Infrared Spectroscopy. J. Am. Chem. Soc. 2004, 126 (43), 14239-14248. https://doi.org/10.1021/ja046818s.

(22) Berggren, G.; Adamska-Venkatesh, A.; Lambertz, C.; Simmons, T. R.; Esselborn, J.; Atta, M.; Gambarelli, S.; Mouesca, J.-M.; Reijerse, E. J.; Lubitz, W.; Happe, T.; Artero, V.; Fontecave, M. Biomimetic Assembly and Activation of [FeFe]-Hydrogenases. Nature 2013, 499 (7456), 66-69. https://doi.org/10.1038/nature12239.

(23) Esselborn, J.; Lambertz, C.; Adamska-Venkatesh, A.; Simmons, T.; Berggren, G.; Noth, J.; Siebel, J. F.; Hemschemeier, A.; Artero, V.; Reijerse, E.; Fontecave, M.; Lubitz, W.; Happe, T. Spontaneous Activation of [FeFe]-Hydrogenases by an Inorganic [2Fe] Active Site Mimic. Nat. Chem. Biol. 2013, 9, 607-609. https://doi.org/10.1038/nchembio.1311.

(24) Noth, J.; Esselborn, J.; Güldenhaupt, J.; Brünje, A.; Sawyer, A.; Apfel, U.-P.; Gerwert, K.; Hofmann, E.; Winkler, M.; Happe, T. [FeFe]-Hydrogenase with Chalcogenide Substitutions at the H-Cluster Maintains Full H2 Evolution Activity. Angew. Chemie Int. Ed. 2016, 55, 8396-8400. 
https://doi.org/10.1002/anie.201511896.

(25) Kertess, L.; Wittkamp, F.; Sommer, C.; Esselborn, J.; Rüdiger, O.; Reijerse, E.; Hofmann, E.; Lubitz, W.; Winkler, M.; Happe, T.; Apfel, U.-P. Chalcogenide Substitution in the [2Fe]-Cluster of [FeFe]Hydrogenases Conserves High Enzymatic Activity. Dalt. Trans. 2017, 46, 16947-16958. https://doi.org/10.1039/C7DT03785F.

(26) Sommer, C.; Richers, C. P.; Lubitz, W.; Rauchfuss, T. B.; Reijerse, E. J. A [RuRu] Analogue of an [FeFe]-Hydrogenase Traps the Key Hydride Intermediate of the Catalytic Cycle Angewandte. Angew. Chemie Int. Ed. 2018, 57, 5429 -5432. https://doi.org/10.1002/anie.201801914.

(27) Einsle, O.; Rees, D. C. Structural Enzymology of Nitrogenase Enzymes. Chem. Rev. 2020, 120 (12), 4969-5004. https://doi.org/10.1021/acs.chemrev.0c00067.

(28) Angove, H. C.; Yoo, S. J.; Burgess, B. K.; Münck, E. Mössbauer and EPR Evidence for an All-Ferrous Fe4S4 Cluster with $S=4$ in the Fe Protein of Nitrogenase. J. Am. Chem. Soc. 1997, 119 (37), 87308731. https://doi.org/10.1021/ja9712837.

(29) Eady, R. R. Structure-Function Relationships of Alternative Nitrogenases. Chem. Rev. 1996, 96 (7), 3013-3030. https://doi.org/10.1021/cr950057h.

(30) Pickett, C. J.; Vincent, K. A.; Ibrahim, S. K.; Gormal, C. A.; Smith, B. E.; Fairhurst, S. A.; Best, S. P. Synergic Binding of Carbon Monoxide and Cyanide to the FeMo Cofactor of Nitrogenase. Chemistry (Easton). 2004, 10, 4770-4776. https://doi.org/10.1002/chem.200400382.

(31) Lee, H. I.; Cameron, L. M.; Hales, B. J.; Hoffman, B. M. CO Binding to the FeMo Cofactor of COInhibited Nitrogenase: $13 \mathrm{CO}$ and 1H Q-Band ENDOR Investigation. J. Am. Chem. Soc. 1997, 119 (42), 10121-10126. https://doi.org/10.1021/ja9715096.

(32) George, S. J.; Ashby, G. A.; Wharton, C. W.; Thorneley, R. N. F. Time-Resolved Binding of Carbon Monoxide to Nitrogenase Monitored by Stopped-Flow Infrared Spectroscopy. J. Am. Chem. Soc. 1997, 7 (9), 6450-6451. https://doi.org/10.1021/ja971088s.

(33) Yang, Z. Y.; Seefeldt, L. C.; Dean, D. R.; Cramer, S. P.; George, S. J. Steric Control of the Hi-CO MoFe Nitrogenase Complex Revealed by Stopped-Flow Infrared Spectroscopy. Angew. Chemie - Int. Ed. 2011, 50 (1), 272-275. https://doi.org/10.1002/anie.201005145.

(34) Paengnakorn, P.; Ash, P. A.; Shaw, S.; Danyal, K.; Chen, T.; Dean, D. R.; Seefeldt, L. C.; Vincent, K. A. Infrared Spectroscopy of the Nitrogenase MoFe Protein under Electrochemical Control: Potential-Triggered CO Binding. Chem. Sci. 2017, 8 (2), 1500-1505. https://doi.org/10.1039/C6SC02860H.

(35) Rees, D. C.; Spatzal, T. Structural Characterization of Two CO Molecules Bound to the Nitrogenase Active Site. Angew. Chemie 2020. https://doi.org/10.1002/anie.202015751.

(36) Jasniewski, A. J.; Lee, C. C.; Ribbe, M. W.; Hu, Y. Reactivity, Mechanism, and Assembly of the Alternative Nitrogenases. Chem. Rev. 2020, 120, 5107-5157.

https://doi.org/10.1021/acs.chemrev.9b00704.

(37) Rebelein, J. G.; Stiebritz, M. T.; Lee, C. C.; Hu, Y. Activation and Reduction of Carbon Dioxide by Nitrogenase Iron Proteins. Nat. Chem. Biol. 2017, 13 (2), 147-149.

https://doi.org/10.1038/nchembio.2245. 
(38) Rettberg, L. A.; Stiebritz, M. T.; Kang, W.; Lee, C. C.; Ribbe, M. W.; Hu, Y. Structural and Mechanistic Insights into CO2 Activation by Nitrogenase Iron Protein. Chem. - A Eur. J. 2019, 25 (57), 13078-13082. https://doi.org/10.1002/chem.201903387.

(39) Ferguson-miller, S.; Babcock, G. T. Heme / Copper Terminal Oxidases. Chem. Rev. 1996, 96, 28892907. https://doi.org/10.1021/cr950051s.

(40) Wikström, M.; Krab, K.; Sharma, V. Oxygen Activation and Energy Conservation by Cytochrome c Oxidase. Chem. Rev. 2018, 118 (5), 2469-2490. https://doi.org/10.1021/acs.chemrev.7b00664.

(41) Gorbikova, E. A.; Belevich, I.; Wikström, M.; Verkhovsky, M. I. The Proton Donor for O-O Bond Scission by Cytochrome c Oxidase. Proc. Natl. Acad. Sci. U. S. A. 2008, 105 (31), 10733-10737. https://doi.org/10.1073/pnas.0802512105.

(42) Faxén, K.; Gilderson, G.; Ädelroth, P.; Brzezinski, P. A Mechanistic Principle for Proton Pumping by Cytochrome c Oxidase. Nature 2005, 437 (7056), 286-289. https://doi.org/10.1038/nature03921.

(43) Ishigami, I.; Zatsepin, N. A.; Hikita, M.; Conrad, C. E.; Nelson, G.; Coe, J. D.; Basu, S.; Grant, T. D.; Seaberg, M. H.; Sierra, R. G.; Hunter, M. S.; Fromme, P.; Fromme, R.; Yeh, S. R.; Rousseau, D. L. Crystal Structure of CO-Bound Cytochrome c Oxidase Determined by Serial Femtosecond X-Ray Crystallography at Room Temperature. Proc. Natl. Acad. Sci. U. S. A. 2017, 114 (30), 8011-8016. https://doi.org/10.1073/pnas.1705628114.

(44) Petersen, L. C. The Effect of Inhibitors on the Oxygen Kinetics of Cytochrome c Oxidase. BBA Bioenerg. 1977, 460 (2), 299-307. https://doi.org/10.1016/0005-2728(77)90216-X.

(45) Fiamingo, F. G.; Altschuld, R. A.; Moh, P. P.; Alben, J. O. Dynamic Interactions of CO with A3Fe and $\mathrm{CuB}$ in Cytochrome c Oxidase in Beef Heart Mitochondria Studied by Fourier Transform Infrared Spectroscopy at Low Temperatures. J. Biol. Chem. 1982, 257 (4), 1639-1650. https://doi.org/10.1038/nrc3282.

(46) Yoshikawa, S.; Caughey, W. S. Infrared Evidence of Cyanide Binding to Iron and Copper in Bovine Heart Cytochrome c Oxidase. J. Biol. Chem. 1992, 265 (14), 7945-7958.

(47) Czernuszewicz, R. S.; Macor, K. A.; Johnson, M. K.; Gewirth, A.; Spiro, T. G. Vibrational Mode Structure and Symmetry in Proteins and Analogues Containing Fe4S4 Clusters: Resonance Raman Evidence for Different Degrees of Distortion in HiPIP and Ferredoxin. J. Am. Chem. Soc. 1987, 109 (23), 7178-7187. https://doi.org/10.1021/ja00257a045.

(48) Barth, A. Infrared Spectroscopy of Proteins. Biochim. Biophys. Acta - Bioenerg. 2007, 1767 (9), 1073-1101. https://doi.org/10.1016/j.bbabio.2007.06.004.

(49) Lorenz-Fonfria, V. A. Infrared Difference Spectroscopy of Proteins: From Bands to Bonds. Chem. Rev. 2020, 120 (7), 3466-3576. https://doi.org/10.1021/acs.chemrev.9b00449.

(50) Tavitian, B. A.; Nabedryk, E.; Mäntele, W.; Breton, J. Light-Induced Fourier Transform Infrared (FTIR) Spectroscopic Investigations of Primary Reactions in Photosystem I and Photosystem II. FEBS Lett. 1986, 201 (1), 151-157. https://doi.org/10.1016/0014-5793(86)80589-0.

(51) Moss, D.; Nabedryk, E.; Breton, J.; Mäntele, W. Redox-Linked Conformational Changes in Proteins Detected by a Combination of Infrared Spectroscopy and Protein Electrochemistry. Evaluation of the Technique with Cytochrome C. Eur. J. Biochem. 1990, 187 (3), 565-572. 
(52) Fried, S. D.; Boxer, S. G. Measuring Electric Fields and Noncovalent Interactions Using the Vibrational Stark Effect. Acc. Chem. Res. 2015, 48 (4), 998-1006.

https://doi.org/10.1021/ar500464j.

(53) Lórenz-Fonfría, V. A.; Heberle, J. Proton Transfer and Protein Conformation Dynamics in Photosensitive Proteins by Time-Resolved Step-Scan Fourier-Transform Infrared Spectroscopy. J. Vis. Exp. 2014, No. 88, 1-16. https://doi.org/10.3791/51622.

(54) Fahrenfort, J. Attenuated Total Reflection. Spectrochim. Acta 1961, 17 (7), 698-709. https://doi.org/10.1016/0371-1951(61)80136-7.

(55) Senger, M. Protonation and Reduction Dynamics in [FeFe]-Hydrogenases, Freie Universität Berlin, 2017. https://doi.org/10.17169/refubium-6966.

(56) Ataka, K.; Stripp, S. T.; Heberle, J. Surface-Enhanced Infrared Absorption Spectroscopy to Probe Monolayers of Membrane Proteins. Biochim. Biophys. Acta 2013, 1828 (10), 2283-2293. https://doi.org/10.1016/j.bbamem.2013.04.026.

(57) Heberle, J.; Zscherp, C. ATR/FT-IR Difference Spectroscopy of Biological Matter with Microsecond Time Resolution. Appl. Spectrosc. 1996, 50 (5), 588-596.

https://doi.org/10.1366/0003702963905907.

(58) Nyquist, R. M.; Ataka, K.; Heberle, J. The Molecular Mechanism of Membrane Proteins Probed by Evanescent Infrared Waves. ChemBioChem 2004, 5 (4), 431-436. https://doi.org/10.1002/cbic.200300687.

(59) Tatulian, S. A. Attenuated Total Reflection Fourier Transform Infrared Spectroscopy: A Method of Choice for Studying Membrane Proteins and Lipids. Biochemistry 2003, 42 (41), 11898-11907. https://doi.org/10.1021/bi034235+.

(60) Rich, P. R.; Iwaki, M. Methods to Probe Protein Transitions with ATR Infrared Spectroscopy. Mol. Biosyst. 2007, 3 (6), 398-407. https://doi.org/10.1039/b702328f.

(61) Glassford, S. E.; Byrne, B.; Kazarian, S. G. Recent Applications of ATR FTIR Spectroscopy and Imaging to Proteins. Biochim. Biophys. Acta 2013, 1834 (12), 2849-2858. https://doi.org/10.1016/j.bbapap.2013.07.015.

(62) Nyquist, R. M.; Heitbrink, D.; Bolwien, C.; Wells, T. A.; Gennis, R. B.; Heberle, J. Perfusion-Induced Redox Differences in Cytochrome c Oxidase: ATR/FT-IR Spectroscopy. FEBS Lett. 2001, 505 (1), 63-67. https://doi.org/10.1016/S0014-5793(01)02769-7.

(63) Senger, M.; Mebs, S.; Duan, J.; Shulenina, O.; Laun, K.; Kertess, L.; Wittkamp, F.; Apfel, U.-P.; Happe, T.; Winkler, M.; Haumann, M.; Stripp, S. T. Protonation/Reduction Dynamics at the [4Fe4S] Cluster of the Hydrogen-Forming Cofactor in [FeFe]-Hydrogenases. Phys. Chem. Chem. Phys. 2018, 20 (5), 3128-3140. https://doi.org/10.1039/C7CP04757F.

(64) Hatley, R. H. M.; Mant, A. Determination of the Unfrozen Water Content of Maximally FreezeConcentrated Carbohydrate Solutions. Int. J. Biol. Macromol. 1993, 15 (4), 227-232. https://doi.org/10.1016/0141-8130(93)90042-K.

(65) Kaesz, H. D.; Saillant, R. B. Hydride Complexes of the Transition Metals. Chem. Rev. 1972, 72 (3), 231-281. https://doi.org/10.1021/cr60277a003. 
(66) Land, H.; Ceccaldi, P.; Mészáros, L. S.; Lorenzi, M.; Redman, H. J.; Senger, M.; Stripp, S. T.; Berggren, G. Discovery of Novel [FeFe]-Hydrogenases for Biocatalytic H2-Production. Chem. Sci. 2019, 10 (43), 9941-9948. https://doi.org/10.1039/c9sc03717a.

(67) Goett-Zink, L.; Klocke, J. L.; Bögeholz, L. A. K.; Kottke, T. In-Cell Infrared Difference Spectroscopy of LOV Photoreceptors Reveals Structural Responses to Light Altered in Living Cells. J. Biol. Chem. 2020, 295 (33), 11729-11741. https://doi.org/10.1074/jbc.RA120.013091.

(68) Land, H.; Sekretaryova, A. N.; Huang, P.; Redman, H. J.; Németh, B.; Polidori, N.; Mészáros, L.; Senger, M.; Stripp, S. T.; Berggren, G. Characterization of a Putative Sensory [FeFe]-Hydrogenase Provides New Insight into the Role of the Active Site Architecture. Chem. Sci. 2020, 11, 1278912801. https://doi.org/10.1039/d0sc03319g.

(69) Morild, E. The Theory of Pressure Effects on Enzymes. Adv. Protein Chem. 1981, 34, 93-166. https://doi.org/10.1016/S0065-3233(08)60519-7.

(70) Senger, M.; Mebs, S.; Duan, J.; Wittkamp, F.; Apfel, U.-P.; Heberle, J.; Haumann, M.; Stripp, S. T. Stepwise Isotope Editing of [FeFe]-Hydrogenases Exposes Cofactor Dynamics. Proc. Natl. Acad. Sci. U. S. A. 2016, 113 (30), 8454-8459. https://doi.org/10.1073/pnas.1606178113.

(71) Senger, M.; Eichmann, V.; Laun, K.; Duan, J.; Wittkamp, F.; Knör, G.; Apfel, U.-P.; Happe, T.; Winkler, M.; Heberle, J.; Stripp, S. T. How [FeFe]-Hydrogenase Facilitates Bidirectional Proton Transfer. J. Am. Chem. Soc. 2019, 141 (43), 17394-17403. https://doi.org/10.1021/jacs.9b09225.

(72) Rohde, M.; Grunau, K.; Einsle, O. CO Binding to the FeV Cofactor of CO-reducing Vanadium Nitrogenase at Atomic Resolution. Angew. Chemie Int. Ed. 2020, 1-6. https://doi.org/10.1002/anie.202010790.

(73) Kachalova, G. S.; Popov, A. N.; Bartunik, H. D. A Steric Mechanism for Inhibition of CO Binding to Heme Proteins. Science (80-. ). 1999, 284 (5413), 473-476.

https://doi.org/10.1126/science.284.5413.473.

(74) Siebel, J. F.; Adamska-Venkatesh, A.; Weber, K.; Rumpel, S.; Reijerse, E.; Lubitz, W. Hybrid [FeFe]Hydrogenases with Modified Active Sites Show Remarkable Residual Enzymatic Activity.

Biochemistry 2015, 54 (7), 1474-1483. https://doi.org/10.1021/bi501391d.

(75) Duan, J.; Mebs, S.; Laun, K.; Wittkamp, F.; Heberle, J.; Hofmann, E.; Apfel, U.-P.; Winkler, M.; Senger, M.; Haumann, M.; Stripp, S. T. Geometry of the Catalytic Active Site in [FeFe]Hydrogenase Is Determined by Hydrogen Bonding and Proton Transfer. ACS Catal. 2019, 9 (10), 9140-9149. https://doi.org/10.1021/acscatal.9b02203.

(76) Ogata, H.; Mizoguchi, Y.; Mizuno, N.; Miki, K.; Adachi, S. ichi; Yasuoka, N.; Yagi, T.; Yamauchi, O.; Hirota, S.; Higuchi, Y. Structural Studies of the Carbon Monoxide Complex of [NiFe]Hydrogenase from Desulfovibrio Vulgaris Miyazaki F: Suggestion for the Initial Activation Site for Dihydrogen. J. Am. Chem. Soc. 2002, 124 (39), 11628-11635. https://doi.org/10.1021/ja012645k.

(77) Bagley, K.; Van Garderen, C.; Chen, M.; Duin, E.; Albracht, S. P. J.; Woodruff, W. Infrared Studies on the Interaction of Carbon Monoxide with Divalent Nickel in Hydrogenase from Chromatium Vinosum. Biochemistry 1994, 33, 9229-9236.

(78) Senger, M.; Laun, K.; Soboh, B.; Stripp, S. T. Infrared Characterization of the Bidirectional Oxygen- 
Sensitive [NiFe]-Hydrogenase from E. Coli. Catalysts 2018, 8, 530. https://doi.org/10.3390/catal8110530.

(79) Heitbrink, D.; Sigurdson, H.; Bolwien, C.; Brzezinski, P. Transient Binding of CO to CuB in Cytochrome c Oxidase Is Dynamically Linked to Structural Changes .... Biophys. J. 2002, 82 (January 2002), 1-10.

(80) Leigh, J. S.; Wilson, D. F.; Owen, C. S.; King, T. E. Heme-Heme Interaction in Cytochrome c Oxidase: The Cooperativity of the Hemes of Cytochrome c Oxidase as Evidenced in the Reaction with CO. Arch. Biochem. Biophys. 1974, 160 (2), 476-486. https://doi.org/10.1016/0003-9861(74)90424-X.

(81) Park, E. S.; Andrews, S. S.; Hu, R. B.; Boxer, S. G. Vibrational Stark Spectroscopy in Proteins: A Probe and Calibration for Electrostatic Fields. J. Phys. Chem. B 1999, 103 (45), 9813-9817. https://doi.org/10.1021/jp992329g.

(82) Winkler, M.; Senger, M.; Duan, J.; Esselborn, J.; Wittkamp, F.; Hofmann, E.; Apfel, U.-P.; Stripp, S. T.; Happe, T. Accumulating the Hydride State in the Catalytic Cycle of [FeFe]-Hydrogenases. Nat. Commun. 2017, 8 (16115), 1-7. https://doi.org/10.1038/ncomms16115.

(83) Tai, H.; Higuchi, Y.; Hirota, S. Comprehensive Reaction Mechanisms at and near the Ni-Fe Active Sites of [NiFe] Hydrogenases. Dalt. Trans. 2018, 47 (13), 4408-4423. https://doi.org/10.1039/c7dt04910b.

(84) Ogata, H.; Nishikawa, K.; Lubitz, W. Hydrogens Detected by Subatomic Resolution Protein Crystallography in a [NiFe] Hydrogenase. Nature 2015, 520 (7548), 571-574. https://doi.org/10.1038/nature14110.

(85) Ash, P. A.; Hidalgo, R.; Vincent, K. A. Proton Transfer in the Catalytic Cycle of [NiFe] Hydrogenases: Insight from Vibrational Spectroscopy. ACS Catal. 2017, 7 (4), 2471-2485. https://doi.org/10.1021/acscatal.6b03182.

(86) Tai, H.; Nishikawa, K.; Inoue, S.; Higuchi, Y.; Hirota, S. FT-IR Characterization of the Light-Induced $\mathrm{Ni}$-L2 and Ni-L3 States of [NiFe] Hydrogenase from Desulfovibrio Vulgaris Miyazaki F. J. Phys. Chem. B 2015, 119 (43), 13688-13674. https://doi.org/10.1021/acs.jpcb.5b03075.

(87) Lorent, C.; Katz, S.; Duan, J.; Julia Kulka, C.; Caserta, G.; Teutloff, C.; Yadav, S.; Apfel, U.-P.; Winkler, M.; Happe, T.; Horch, M.; Zebger, I. Shedding Light on Proton and Electron Dynamics in [FeFe] Hydrogenases. J. Am. Chem. Soc. 2020, 142 (12), 5493-5497. https://doi.org/10.1021/jacs.9b13075.

(88) Chen, Z.; Lemon, B. J.; Huang, S.; Swartz, D. J.; Peters, J. W.; Bagley, K. A. Infrared Studies of the CO-Inhibited Form of the Fe-Only Hydrogenase from Clostridium Pasteurianum I: Examination of Its Light Sensitivity at Cryogenic Temperatures. Biochemistry 2002, 41 (6), 2036-2043. https://doi.org/10.1021/bi011510o.

(89) Lyon, E. J.; Shima, S.; Buurman, G.; Chowdhuri, S.; Batschauer, A.; Steinbach, K.; Thauer, R. K. UVA/Blue-Light Inactivation of the "metal-Free" Hydrogenase (Hmd) from Methanogenic Archaea. Eur. J. Biochem. 2003, 271 (1), 195-204. https://doi.org/10.1046/j.1432-1033.2003.03920.x.

(90) Roseboom, W.; De Lacey, A. L.; Fernandez, V. M.; Hatchikian, E. C.; Albracht, S. P. J. The Active Site of the [FeFe]-Hydrogenase from Desulfovibrio Desulfuricans. II. Redox Properties, Light Sensitivity 
and CO-Ligand Exchange as Observed by Infrared Spectroscopy. J. Biol. Inorg. Chem. 2006, 11 (1), 102-118. https://doi.org/10.1007/s00775-005-0040-2.

(91) Mebs, S.; Senger, M.; Duan, J.; Wittkamp, F.; Apfel, U.-P.; Happe, T.; Winkler, M.; Stripp, S. T.; Haumann, M. Bridging Hydride at Reduced H-Cluster Species in [FeFe]-Hydrogenases Revealed by Infrared Spectroscopy, Isotope Editing, and Quantum Chemistry. J. Am. Chem. Soc. 2017, 139 (35), 12157-12160. https://doi.org/10.1021/jacs.7b07548.

(92) Sommer, C.; Adamska-Venkatesh, A.; Pawlak, K.; Birrell, J. A.; Rüdiger, O.; Reijerse, E. J.; Lubitz, W. Proton Coupled Electronic Rearrangement within the H-Cluster as an Essential Step in the Catalytic Cycle of [FeFe] Hydrogenases. J. Am. Chem. Soc. 2017, 139 (4), 1440-1443. https://doi.org/10.1021/jacs.6b12636.

(93) Laun, K.; Baranova, I.; Duan, J.; Kertess, L.; Wittkamp, F.; Apfel, U.-P.; Happe, T.; Senger, M.; Stripp, S. T. Site-Selective Protonation of the One-Electron Reduced Cofactor in [FeFe]Hydrogenase. ChemRxiv 2020. https://doi.org/10.26434/chemrxiv.9970571.v3.

(94) Birrell, J. A.; Pelmenschikov, V.; Mishra, N.; Wang, H.; Yoda, Y.; Rauchfuss, T. B.; Cramer, S. P.; Lubitz, W.; Debeer, S. Spectroscopic and Computational Evidence That [FeFe] Hydrogenases Operate Exclusively with CO-Bridged Intermediates. J. Am. Chem. Soc. 2020, 142 (1), 222-232. https://doi.org/10.1021/jacs.9b09745.

(95) Stripp, S. T.; Mebs, S.; Haumann, M. Temperature Dependence of Structural Dynamics at the Catalytic Cofactor of [FeFe]-Hydrogenase. Inorg. Chem. 2020, 59 (22), 16474-16488. https://doi.org/10.1021/acs.inorgchem.0c02316.

(96) Katz, S.; Noth, J.; Horch, M.; Shafaat, H. S.; Happe, T.; Hildebrandt, P.; Zebger, I. Vibrational Spectroscopy Reveals the Initial Steps of Biological Hydrogen Evolution. Chem. Sci. 2016, 7, 67466752. https://doi.org/10.1039/C6SC01098A.

(97) Lemon, B. J.; Peters, J. W. Photochemistry at the Active Site of the Carbon Monoxide Inhibited Form of the Iron-Only Hydrogenase (CpI). J. Am. Chem. Soc. 2000, 122 (15), 3793-3794. https://doi.org/10.1021/ja9943703.

(98) Lubner, C. E.; Applegate, A. M.; Knörzer, P.; Ganago, A.; Bryant, D. A.; Happe, T.; Golbeck, J. H. Solar Hydrogen-Producing Bionanodevice Outperforms Natural Photosynthesis. Proc. Natl. Acad. Sci. U. S. A. 2011, 108 (52), 20988-20991. https://doi.org/10.1073/pnas.1114660108.

(99) Utschig, L. M.; Soltau, S. R.; Tiede, D. M. Light-Driven Hydrogen Production from Photosystem ICatalyst Hybrids. Curr. Opin. Chem. Biol. 2015, 25, 1-8.

https://doi.org/10.1016/j.cbpa.2014.11.019.

(100) Adam, D.; Bösche, L.; Castaneda-Losada, L.; Winkler, M.; Apfel, U.-P.; Happe, T. SunlightDependent Hydrogen Production by Photosensitizer / Hydrogenase Systems. ChemSusChem 2017, 10 (5), 894-902. https://doi.org/10.1002/cssc.201601523.

(101) Tai, H.; Nishikawa, K.; Higuchi, Y.; Mao, Z.-W.; Hirota, S. Cysteine SH and Glutamate COOH Contributions to [NiFe] Hydrogenase Proton Transfer Revealed by Highly Sensitive FT-IR Spectroscopy. Angew. Chemie Int. Ed. 2019, 58 (38), 13285-13290. https://doi.org/10.1002/anie.201904472. 
(102) Hellwig, P.; Rost, B.; Kaiser, U.; Ostermeier, C.; Michel, H.; Mäntele, W. Carboxyl Group Protonation upon Reduction of the Paracoccus Denitrificans Cytochrome c Oxidase: Direct Evidence by FTIR Spectroscopy. FEBS Lett. 1996, 385 (1-2), 53-57. https://doi.org/10.1016/00145793(96)00342-0.

(103) Nyquist, R. M.; Heitbrink, D.; Bolwien, C.; Gennis, R. B.; Heberle, J. Direct Observation of Protonation Reactions during the Catalytic Cycle of Cytochrome c Oxidase. Proc. Natl. Acad. Sci. 2003, 100 (15), 8715-8720. https://doi.org/10.1073/pnas.1530408100.

(104) Okuno, D.; Iwase, T.; Shinzawa-Itoh, K.; Yoshikawa, S.; Kitagawa, T. FTIR Detection of Protonation/Deprotonation of Key Carboxyl Side Chains Caused by Redox Change of the CuAHeme a Moiety and Ligand Dissociation from the Heme A3-CuB Center of Bovine Heart Cytochrome c Oxidase. J. Am. Chem. Soc. 2003, 125 (24), 7209-7218. https://doi.org/10.1021/ja021302z.

(105) Maréchal, A.; Hartley, A. M.; Warelow, T. P.; Meunier, B.; Rich, P. R. Comparison of Redox and Ligand Binding Behaviour of Yeast and Bovine Cytochrome c Oxidases Using FTIR Spectroscopy. Biochim. Biophys. Acta - Bioenerg. 2018, 1859 (9), 705-711. https://doi.org/10.1016/j.bbabio.2018.05.018.

(106) Dodia, R.; Maréchal, A.; Bettini, S.; Iwaki, M.; Rich, P. R. IR Signatures of the Metal Centres of Bovine Cytochrome c Oxidase: Assignments and Redox-Linkage. Biochem. Soc. Trans. 2013, 41 (5), 1242-1248. https://doi.org/10.1042/BST20130087.

(107) Yan, L.; Dapper, C. H.; George, S. J.; Wang, H.; Mitra, D.; Dong, W.; Newton, W. E.; Cramer, S. P. Photolysis of Hi-CO Nitrogenase - Observation of a Plethora of Distinct CO Species Using Infrared Spectroscopy. Eur. J. Inorg. Chem. 2011, 2064-2074. https://doi.org/10.1002/ejic.201100029.

(108) Pollock, R. C.; Lee, H.; Cameron, L. M.; DeRose, V. J.; Hales, B. J.; Orme-Johnson, W. H.; Hoffman, B. M. Investigation of CO Bound to Inhibited Forms of Nitrogenase MoFe Protein by 13C ENDOR. J. Am. Chem. Soc. 1995, 117, 8686-8687. https://doi.org/10.1021/ja00138a033.

(109) Maskos, Z.; Hales, B. J. Photo-Lability of CO Bound to Mo-Nitrogenase from Azotobacter Vinelandii. J. Inorg. Biochem. 2003, 93 (1-2), 11-17. https://doi.org/10.1016/S01620134(02)00480-4.

(110) Appel, A. M.; Bercaw, J. E.; Bocarsly, A. B.; Dobbek, H.; Dubois, D. L.; Dupuis, M.; Ferry, J. G.; Fujita, E.; Hille, R.; Kenis, P. J. A.; Kerfeld, C. A.; Morris, R. H.; Peden, C. H. F.; Portis, A. R.; Ragsdale, S. W.; Rauchfuss, T. B.; Reek, J. N. H.; Seefeldt, L. C.; Thauer, R. K.; Waldrop, G. L. Frontiers, Opportunities, and Challenges in Biochemical and Chemical Catalysis of CO2 Fixation. Chem. Rev. 2013, 113 (8), 6621-6658. https://doi.org/10.1021/cr300463y.

(111) Soboh, B.; Stripp, S. T.; Bielak, C.; Lindenstrauß, U.; Braussemann, M.; Javaid, M.; Hallensleben, M.; Granich, C.; Herzberg, M.; Heberle, J.; Sawers, R. G. The [NiFe]-Hydrogenase Accessory Chaperones HypC and HybG of Escherichia Coli Are Iron- and Carbon Dioxide-Binding Proteins. FEBS Lett. 2013, 587 (16), 2512-2516. https://doi.org/10.1016/j.febslet.2013.06.055.

(112) Shiro, Y. Structure and Function of Bacterial Nitric Oxide Reductases: Nitric Oxide Reductase, Anaerobic Enzymes. Biochim. Biophys. Acta-Bioenerg. 2012, 1817 (10), 1907-1913. https://doi.org/10.1016/j.bbabio.2012.03.001. 
(113) Giuffrè, A.; Stubauer, G.; Sarti, P.; Brunori, M.; Zumft, W. G.; Buse, G.; Soulimane, T. The HemeCopper Oxidases of Thermus Thermophilus Catalyze the Reduction of Nitric Oxide: Evolutionary Implications. Proc. Natl. Acad. Sci. U. S. A. 1999, 96 (26), 14718-14723.

https://doi.org/10.1073/pnas.96.26.14718.

\section{Table of Contents}

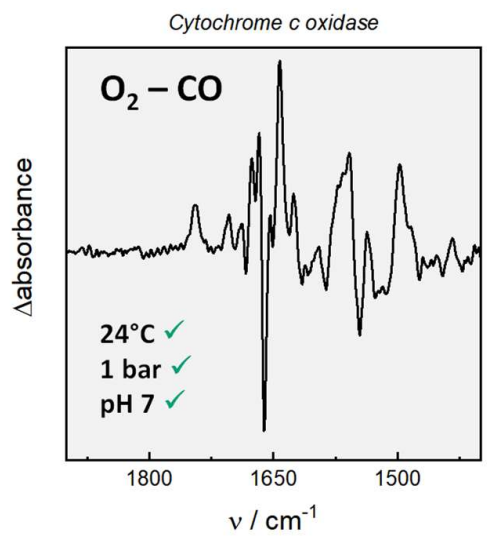

\section{Gas-processing metalloenzymes}

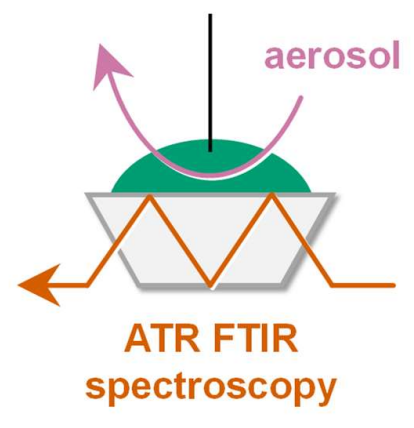

Operando ATR FTIR spectroscopy can be used to investigate a variety of gas-processing metalloenzymes. It is demonstrated how gas exchange experiments yield sensitive FTIR difference spectra, notably under biologically relevant conditions. 